\title{
Article \\ Abiotic Stress Induces Morphological, Physiological, and Genetic Changes in Orthosiphon stamineus Benth. In Vitro Cultures
}

\author{
Hanisah Ali ${ }^{1}$, Nurhanani Sallahuddin ${ }^{1}$, Nur Haziqah Ahmed Shamsudin ${ }^{1}$, Nurul Amalina Mohd Zain ${ }^{1}$, \\ Mohd Hafiz Ibrahim ${ }^{2}$ and Jamilah Syafawati Yaacob $1,3, *$ (D)
}

check for

Citation: Ali, H.; Sallahuddin, N.; Ahmed Shamsudin, N.H.; Mohd Zain, N.A.; Ibrahim, M.H.; Yaacob, J.S. Abiotic Stress Induces Morphological, Physiological, and Genetic Changes in Orthosiphon stamineus Benth. In Vitro Cultures. Horticulturae 2022, 8, 153. https:// doi.org/10.3390/horticulturae8020153 Academic Editor: Sergio Ruffo Roberto

Received: 30 December 2021 Accepted: 1 February 2022 Published: 11 February 2022

Publisher's Note: MDPI stays neutral with regard to jurisdictional claims in published maps and institutional affiliations.

Copyright: (C) 2022 by the authors. Licensee MDPI, Basel, Switzerland. This article is an open access article distributed under the terms and conditions of the Creative Commons Attribution (CC BY) license (https:// creativecommons.org/licenses/by/ $4.0 /)$.
1 Institute of Biological Sciences, Faculty of Science, Universiti Malaya, Kuala Lumpur 50603, Malaysia; hanisahisb@gmail.com (H.A.); nurhanani96@gmail.com (N.S.); haziqahshamsudin@gmail.com (N.H.A.S.); amalina86@um.edu.my (N.A.M.Z.)

2 Department of Biology, Faculty of Science, Universiti Putra Malaysia, Serdang 43400, Malaysia; mhafiz_ibrahim@upm.edu.my

3 Centre for Research in Biotechnology for Agriculture (CEBAR), Universiti Malaya, Kuala Lumpur 50603, Malaysia

* Correspondence: jamilahsyafawati@um.edu.my; Tel.: +60-3-79674090

\begin{abstract}
Orthosiphon stamineus is a well-known medicinal herb that has long been used as a traditional treatment for a variety of ailments and disorders. In this study, in vitro grown O. stamineus plantlets were subjected to various stress factors to elucidate the effects of these stresses on the occurrence of somaclonal variation in this species. Murashige and Skoog (MS) media supplemented with $2.0 \mathrm{mg} / \mathrm{L}$ kinetin plus $0.5 \mathrm{mg} / \mathrm{L}$ IAA was identified as the optimum in vitro regeneration media $(\mathrm{OM})$. The data analysis confirmed the clonal nature of the resulting plantlets. The plantlets were also exposed to various stress factors such as high salinity, abscisic acid (ABA), and high cytokinin concentrations, by subculturing the plantlets on $\mathrm{OM}$ added with various concentrations of $\mathrm{NaCl}$, $\mathrm{ABA}$, and high kinetin levels. Exposure to the various stress factors was observed to result in the occurrence of somaclonal variation in O. stamineus, where the incidence of hyperhydricity was found to be the most prominent. An ISSR analysis revealed $70.12 \%$ polymorphism among the variants. The results showed that the chlorophyll content and photosynthetic ability of plantlets were reduced when the abiotic stress levels increased.
\end{abstract}

Keywords: Orthosiphon stamineus; plant tissue culture; ISSR; hyperhydricity; photosynthetic ability

\section{Introduction}

For centuries, herb plants have been widely utilized as a main source of medicine and pharmaceuticals. Despite advancements in modern healthcare, traditional medicines and practices are still used by people throughout the world, particularly in impoverished nations. It has been reported that traditional herbs play major roles in primary healthcare in $70-80 \%$ of the world population [1]. Orthosiphon stamineus, also known as "Misai Kucing" or Cat's Whiskers in Malaysia, is a Lamiaceae herbaceous plant that is commonly grown in tropical countries such as India, Malaysia, and China (Southeast Asia). It thrives on moist soil and is commonly seen in temperate and tropical gardens. The flowers feature long, wispy filaments that resemble cats' whiskers, while the leaves are green, simple, and placed in opposing pairs. Its bloom comes in two colors, i.e., white and light purple. This species is a well-known medicinal plant that is commonly consumed as an herbal tea or "Java tea" throughout Southeast Asia and tropical Australia. It has also been identified as a high value economically important herb, based on Malaysia's National Key Economic Areas (NKEA).

The leaves of $O$. stamineus are commonly consumed as a drink in Malaysia and Indonesia to cure inflammation, ingestion, and diabetes mellitus. The leaves are also used 
in the treatment of a variety of illnesses and health problems because they are reported to have anti-inflammatory, antibacterial, antioxidant, and other benefits [2]. O. stamineus has a lot of economic potential, as it contains secondary metabolites with intriguing biological properties. Thus far, 116 compounds have been isolated from this plant, such as diterpenes, flavones, and triterpenes. O. stamineus extract possesses significant antioxidant ability, due to one of its components, i.e., a caffeic acid ester known as rosmarinic acid. In addition, the plant has also been found to have anti-inflammatory, antioxidant, antibacterial, and antiangiogenic effects [3].

Traditionally, this herb is propagated vegetatively through mature stems. This approach seemed to be plausible, however, the supply was insufficient to meet market demand [4] and slowed down mass propagation of this species [5]. Currently, plant growth regulators are widely employed in the production of a variety of crops and seed germination [6], in order to obtain a huge yield in a shorter time frame. This is a cogent alternative, but this method needs extensive human and land resources, and therefore, as the technology advances, there is an obvious option to resolve this problem. In vitro micropropagation can serve as a reliable alternative, as it allows for mass propagation of plants in a shorter time. This method can also provide an alternative for growing selected species in unsuitable climate conditions or extreme weather.

Although in vitro micropropagation appears to be effective, tissue culture techniques also create stress conditions while promoting a faster growth and multiplication of shoots, which frequently results in plantlets with deformed and aberrant morphology, anatomy, and physiology [7]. Due to the extremely stressful in vitro environment, tissue culture plantlets have shown higher rates of single-gene mutations, chromosomal breakages, transposable element activations, quantitative trait variations, and changes in normal DNA methylation patterns [8]. Alternate forms between clonal samples may develop due to somaclonal variation among samples. In order to confirm the genetic integrity, extensive research on genetic fidelity has been conducted on micropropagated plantlets. Because various genomes react differently to stress-induced variation, it is possible that somaclonal variation contains genotypic components that influence the variant. ISSR analysis has been widely used to detect polymorphism in genomic DNA due to a number of advantages, including the fact that it has a relatively rapid experimental process that only requires a small amount of DNA sample, and it is cost-effective.

An efficient micropropagation technique has been developed for this species, as previously reported [9]. However, to date, information is still scarce on the effect of salt, ABA, and high cytokinin (kinetin) levels in causing stress on plants (especially O. stamienus) and elucidation of the genetic, morphological, and physiological changes that have been caused. Thus, this study was designed and conducted with the aim to evaluate the effects of exposure to abiotic stress factors (exposure to salinity, abscisic acid or ABA, and high kinetin levels) on the occurrence of somaclonal variation in this species. The genetic distance between the somaclonal variants to the mother plant was also assessed using ISSR markers. Subsequently, in order to fully comprehend the effects of stress on somaclonal variation, changes in the plants' physiological and biochemical properties were also evaluated and compared.

\section{Materials and Methods}

\subsection{Plant Material and Culture Conditions}

Nodal explants of Orthosiphon stamineus (KLU46468) were excised and surface sterilized, as previously reported [9]. Then, the explants were cultured on either MS [10] basal media (control) or optimum regeneration media $(\mathrm{OM})$ composed of MS added with $0.5 \mathrm{mg} / \mathrm{L}$ IAA and $2.0 \mathrm{mg} / \mathrm{L}$ kinetin. The media were solidified using $2 \mathrm{~g} / \mathrm{L}$ Gelrite Gellan Gum (Duchefa Biochemie B.V, 2003, RV Haarlem, The Netherlands). Approximately $1 \mathrm{~cm}$ of the internode region containing the petioles was excised from mature stems of $O$. stamineus. All leaves and axillary buds were removed. Each petiole region was retained at about $0.3-0.5 \mathrm{~cm}$ long. Most of the explants had 2 nodes on each explant. 
In order to evaluate the effects of stress on the occurrence of somaclonal variation in this species, the nodal explants were exposed to several abiotic stress factors such as high salinity, ABA (a phytohormone involved in abiotic stress signaling), and high cytokinin (kinetin) concentrations in vitro. For this purpose, the nodal explants were cultured onto the stress media composed of $\mathrm{OM}$ plus various concentrations of $\mathrm{NaCl}(0.001-0.004 \mathrm{mg} / \mathrm{L})$ or ABA (1.0-6.0 $\mu \mathrm{M})$. Meanwhile, the preparation of high cytokinin stress media were similar to the preparation of OM, but with higher concentrations of kinetin (from $2.5 \mathrm{mg} / \mathrm{L}$ to $4.0 \mathrm{mg} / \mathrm{L}$ ). The explants were cultured in a universal container before being transferred to a large tissue culture jar. The tissue culture jars used for subsequent subcultures were of the same size.

\subsection{Morphological Observation}

The plantlets were observed weekly to detect any changes in the number of shoots, leaves, roots, production of callus, as well as any occurrence of hyperhydricity. The morphological data were recorded after the third subculture. The experiments were conducted following a randomized complete block design (RCBD) of triplicates of $n=10$. Data obtained were analyzed using the IBM SPSS Statistics 19 Software (International Business Machines Corp., Armonk, NY, USA). A statistical variance analysis was conducted using analysis of variance (ANOVA) and Duncan's multiple range test (DMRT) at 5\% significance level. The multiplication index was analyzed by calculating the number of newly formed shoots per initial shoot tip recorded [11]. The concentration of stress factors that resulted in the highest frequency of variations (number of abnormal leaves) were chosen for subsequent experiments.

\subsection{Sample Harvest}

The leaf samples were harvested after the third subculture. Some leaf samples were also collected for physiological and biochemical analyses. Approximately $0.5 \mathrm{~g}$ of leaves were weighed and cut into small pieces before being placed in $1.5 \mathrm{~mL}$ tubes. The tubes were carefully labeled and stored at $-80^{\circ} \mathrm{C}$ in a freezer, until further use for the ISSR-based genetic fidelity tests.

\subsection{DNA Extraction and ISSR Analysis}

DNA extraction was conducted using an i-genomic Plant DNA Extraction Mini Kit (Intron Biotechnology Inc., Seongnam-si, South Korea), following the manufacturer's protocol. The DNA concentration of the samples was determined using a nanophotometer (IMPLEN, Germany) and standardized to $50 \mathrm{ng}$ for each PCR reaction. Overall, a total of 20 ISSR primers were used in the analysis, but only 10 primers produced satisfactory amplification for this species and reported in this study [9]. The 10 primers used are listed in Table 1. A PCR master mix (Invitrogen, Waltham, MA, USA) was prepared using the components as listed in Table 2. A total of $20 \mu \mathrm{L}$ master mix with the DNA template was subjected to PCR reaction using a Mastercycler Nexus PCR cycler (Eppendorf, Petaling Jaya, Malaysia).

The PCR conditions used in the ISSR analysis are summarized in Table 3. The denaturation, annealing, and extension processes were conducted in 35 cycles. The amplified products were resolved in $1.5 \%$ agarose gel (1X TAE), and then, visualized under UV light using a gel documentation system (Alpha Innotech, San Leandro, CA, USA). A TrackIt ${ }^{\mathrm{TM}}$ $1 \mathrm{~Kb}$ Plus DNA ladder (Invitrogen, USA) was used for the sizing of the DNA bands.

All data were compiled as a binary character matrix. The bands were scored as presence (1) and absence (0) for each sample through manual scoring, and triple checked to minimize errors. Faint and ambiguous bands were excluded from the statistical analysis. Only clear and reproducible bands were included in the data evaluation. Jaccard's coefficients were used to calculate the genetic dissimilarity between the samples using Darwin 6.0 software. A phylogenetic tree was generated to observe the phylogenetic relationship 
between the plantlets grown on the stress media, the mother plant (in vivo), media without PGRs (MS0), and optimum regeneration media (OM).

Table 1. Ten ISSR primers used in this study.

\begin{tabular}{ccc}
\hline Primers Code & Sequence $\mathbf{5}^{\prime}-\mathbf{3}^{\prime}$ & Annealing Temperature $\left({ }^{\circ} \mathbf{C}\right)$ \\
\hline UBC807 & $(\mathrm{AG})_{8} \mathrm{~T}$ & 46.5 \\
$\mathrm{UBC} 829$ & $(\mathrm{TG})_{8} \mathrm{C}$ & 52.5 \\
$\mathrm{UBC} 835$ & $(\mathrm{AG})_{8} \mathrm{YC}$ & 50 \\
$\mathrm{UBC} 836$ & $(\mathrm{AG})_{8} \mathrm{YA}$ & 48 \\
$\mathrm{UBC} 840$ & $(\mathrm{GA})_{8} \mathrm{YT}$ & 46.5 \\
$\mathrm{UBC} 841$ & $(\mathrm{GA})_{8} \mathrm{YC}$ & 52 \\
$\mathrm{UBC} 845$ & $(\mathrm{CT})_{8} \mathrm{RG}$ & 47.5 \\
$\mathrm{UBC} 854$ & $(\mathrm{TC})_{8} \mathrm{RG}$ & 50 \\
$\mathrm{UBC} 855$ & $(\mathrm{AC})_{8} \mathrm{YT}$ & 53 \\
$\mathrm{UBC} 856$ & $(\mathrm{AC})_{8} \mathrm{YA}$ & 54 \\
\hline
\end{tabular}

Table 2. Component in each total reaction volume.

\begin{tabular}{ccc}
\hline PCR Constituent & Final Concentration & Volume $(\mu \mathrm{L})$ \\
\hline Template DNA & $50 \mathrm{ng} / \mu \mathrm{L}$ & $\mathrm{x} \mu \mathrm{L}$ \\
$10 \times$ PCR buffer & $1 \times$ & 2 \\
$25 \mathrm{mM}$ Magnesium chloride $\left(\mathrm{MgCl}_{2}\right)$ & $50 \mathrm{mM}$ & 2 \\
$5 \mathrm{mM}$ dNTPs & $4 \mathrm{mM}$ & 0.5 \\
$1 \mathrm{mM}$ Primer & $0.25 \mathrm{mM}$ & 0.25 \\
Taq polymerase $(5 \mathrm{U} / \mu \mathrm{L})$ & $2.5 \mathrm{U}$ & 0.5 \\
$10 \mathrm{mg} / \mathrm{mL} \mathrm{BSA}$ & $4 \mathrm{mg}$ & 0.4 \\
ddH $\mathrm{H}_{2} \mathrm{O}$ & & $\mathrm{y} \mu \mathrm{L}$ \\
Total & & $20 \mu \mathrm{L}$ \\
\hline
\end{tabular}

Table 3. PCR conditions used in the ISSR analysis.

\begin{tabular}{ccc}
\hline Phase & Temperature $\left({ }^{\circ} \mathbf{C}\right)$ & Duration $(\mathbf{m i n})$ \\
\hline Initial denaturation & 94.0 & 5 \\
Denaturation & 94.0 & 1 \\
Annealing & According to Table 1 & 1 \\
Extension & 72.0 & 2 \\
Final extension & 72.0 & 10 \\
\hline
\end{tabular}

\subsection{Physiological and Biochemical Analysis}

In this study, the regenerants were also subjected to several physiological and biochemical analyses. This is important to evaluate the effect of somaclonal variation brought upon by the abiotic stress factors on the physiological and biological processes of the plants.

\subsubsection{Measurement of Chlorophyll Content}

Total chlorophyll content was measured using fresh weight basis. The leaves were weighed and ground using mortar and pestle. The ground samples were immersed in $15 \mathrm{~mL}$ of $100 \%$ methanol. The samples were chilled for $24 \mathrm{~h}$ and the absorbance was read at wavelengths of $665.2 \mathrm{~nm}$ and $652.4 \mathrm{~nm}$. The absorbance values were recorded using a Sunrise microplate reader (Tecan, Grödig 5080, Austria) and the contents of chlorophyll a and $b$ were calculated using the formula shown below [12]:

$$
\begin{aligned}
& \mathrm{C}_{\mathrm{a}}(\mu \mathrm{g} / \mathrm{mL})=16.72 \mathrm{~A}_{665.2}-9.16 \mathrm{~A}_{652.4} \\
& \mathrm{C}_{\mathrm{b}}(\mu \mathrm{g} / \mathrm{mL})=34.09 \mathrm{~A}_{652.4}-15.28 \mathrm{~A}_{665.2}
\end{aligned}
$$




\subsubsection{In Situ Chlorophyll Content (SPAD Method)}

In situ chlorophyll content was analyzed prior to sample harvest. The relative leaf chlorophyll contents were measured using a SPAD 502 m (Minolta Inc., Alameda, CA, USA). The relative SPAD readings were recorded from five points per leaf. Then, the same leaf samples were also used in the biochemical analysis to determine the chlorophyll content, as described in Section 2.5.1.

\subsubsection{Malondialdehyde (MDA) Content Determination}

In this study, the thiobarbituric acid (TBA) technique was used to evaluate the quantity of malondialdehyde (MDA) produced by lipid peroxidation of the plant components [13]. First, $0.1 \mathrm{~g}$ of ground $(0.25 \mathrm{~mm})$ sample was homogenized using mortar and pestle in $0.5 \%$ trichloroacetic acetic acid (TCA, $1 \mathrm{~mL}$ ). The homogenate was centrifuged at $9000 \mathrm{rpm}$ for $20 \mathrm{~min}$. The supernatant $(0.5 \mathrm{~mL})$ was mixed with $20 \%$ TCA $(2.5 \mathrm{~mL})$ containing $0.5 \%$ TBA, heated in a boiling water bath for $30 \mathrm{~min}$, and allowed to cool in an ice bath quickly. The supernatant was centrifuged at $9000 \mathrm{rpm}$ for $10 \mathrm{~min}$. The final supernatant was used for determination of the MDA contents.

\subsubsection{Leaf Gas Exchange Measurement}

The measurements were obtained using a LICOR 6400 Portable Photosynthesis System, which was a closed infrared gas analyzer (IRGA, Licor. Inc. Omaha, NE, USA). The instrument was warmed for $30 \mathrm{~min}$ before being used and calibrated with the ZERO IRGA mode. Two steps were required in the calibration process: first, the initial zeroing process for the built-in flow meter; and second, zeroing process for the infra-red gas analyzer.

The measurements were conducted under ideal conditions of $400 \mu \mathrm{mol} / \mathrm{mol} \mathrm{CO}$, $30{ }^{\circ} \mathrm{C}$ cuvette temperature, $60 \%$ relative humidity, and a $500 \mathrm{~cm}^{3} / \mathrm{min}$ air flow rate, as well as an adjusted cuvette condition of $800 \mu \mathrm{mol} / \mathrm{m} / \mathrm{s}$ photosynthetically photon flux density (PPFD). Between 9:00 a.m. and 11:00 a.m., the measurements of gas exchange were taken using completely expanded young leaves, numbered three and four, from the plant apex, to record the net photosynthesis rate (A). The operation was automatic, and the data were stored in the LI-6400 console and analyzed with the Photosyn Assistant software (Version 3, Lincoln Inc., Columbus, OH, USA).

\subsubsection{Chlorophyll Fluorescence Measurement}

The chlorophyll fluorescence was measured on a completely extended leaf of the second leaf. Light exclusion clips were mounted to the central region of the leaf surface and the leaves were darkened for $15 \mathrm{~min}$. A portable chlorophyll fluorescence meter was used to measure the fluorescence of chlorophyll (Handy PEA, Hansatech Instruments Ltd., Kings Lynn, UK). The measurements were taken for a total of $5 \mathrm{~s}$. Emitting diodes were used to generate the fluorescence responses. This procedure yielded the following results: $F_{\mathrm{o}}$ (initial fluorescence), $\mathrm{F}_{\mathrm{m}}$ (maximum fluorescence), $\mathrm{F}_{\mathrm{v}}$ (variable fluorescence), and PI (performance index).

\subsubsection{Statistical Analysis}

Data recorded were analyzed using IBM SPSS Statistics 19 Software (International Business Machines Corp., Armonk, NY, USA). The statistical analysis was conducted using analysis of variance (ANOVA) and Duncan's multiple range test (DMRT) at $5 \%$ significance level.

\section{Results}

\subsection{Morphological Observation}

The use of the regeneration media OM (MS media supplemented with $0.5 \mathrm{mg} / \mathrm{L}$ IAA and $2.0 \mathrm{mg} / \mathrm{L}$ kinetin) yielded production of clonal plantlets, as ascertained by the outcomes of the ISSR analysis [9]. The uniform morphological characteristics between the in vitro grown plantlets and the mother plant further supported the outcome of the ISSR analysis results, thus, confirming the clonal nature of the plantlets [9]. In this study, the mor- 
phological data of stress-treated plantlets were collected after the third subculture. Several types of variation were observed in the stressed plants such as hyperhydricity (vitrification), leaf variegation, dwarfism, and formation of underdeveloped leaves. Nevertheless, this study focused on the occurrence of hyperhydricity in the samples, as it occurred more frequently than other variations (data not shown). All samples were observed weekly to detect any occurrence of hyperhydricity. In tissue culture-generated plants, hyperhydricity occurs when plantlets experience excessive hydration, low lignification, impaired stomatal function, and reduced mechanical strength. This gives the plant a translucent appearance, which is caused by a lack of chlorophyll and high water content.

\subsection{Morphology of Plantlets Exposed to Salinity Stress}

Figure 1 shows the plantlets subjected to $0.001-0.004 \mathrm{mg} / \mathrm{L} \mathrm{NaCl}$ stress. Under salinity stress, the leaf became stunted and lost its green pigment, making it appear white. The leaves were also translucent, which indicated hyperhydricity. The height of the plantlets decreased as the $\mathrm{NaCl}$ concentration increased, and it was also significantly lower than MS0 and OM plantlets (Table 4). The development of roots was also considerably hindered in salt-stressed plantlets, indicating that salinity stress had a negative impact on root formation. The size of the leaves was also relatively smaller than the size of the leaves produced on $\mathrm{OM}$ and MS0. The number of leaves also significantly decreased as the concentration of $\mathrm{NaCl}$ increased. The leaf margins were observed to be non-serrated (Figure 1), in contrast, phenotypically normal leaves of Orthosiphon stamineus have serrated margins. The multiplication index, on the other hand, did not differ significantly throughout the $\mathrm{NaCl}$ concentrations used.

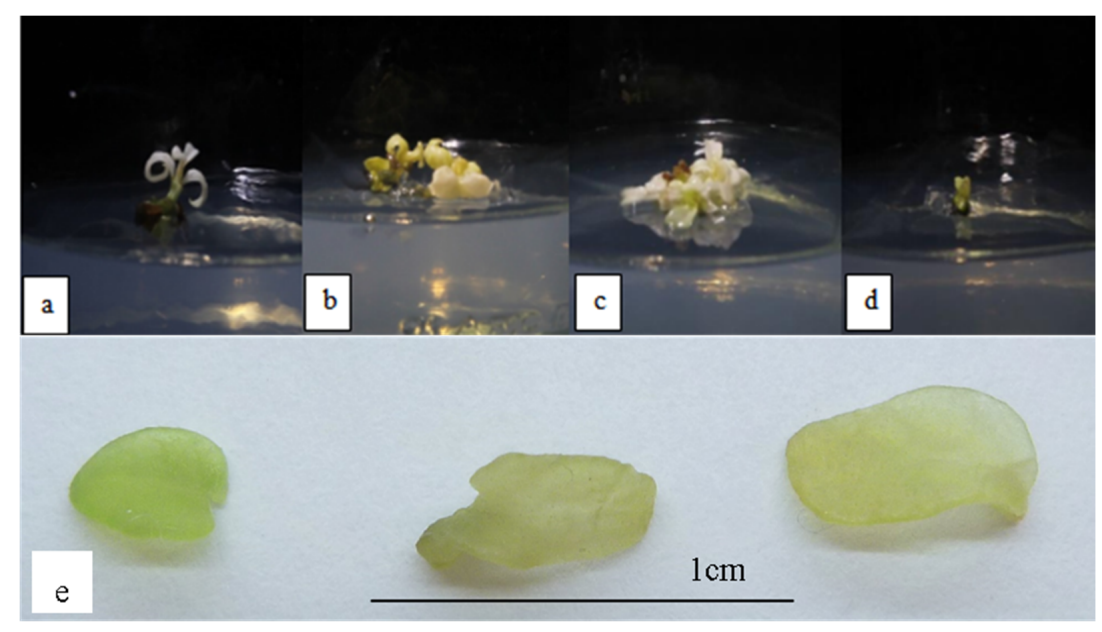

Figure 1. O. stamineus subjected to $\mathrm{NaCl}$ stress harvested after the third subcultures: (a) $0.001 \mathrm{mg} / \mathrm{L}$ $\mathrm{NaCl}$; (b) $0.002 \mathrm{mg} / \mathrm{L} \mathrm{NaCl}$; (c) $0.003 \mathrm{mg} / \mathrm{L} \mathrm{NaCl}$; (d) $0.004 \mathrm{mg} / \mathrm{L} \mathrm{NaCl}$; (e) hyperhydricity observed in leaves subjected to $\mathrm{NaCl}$ stress.

\subsection{Morphology of Plantlets Exposed to ABA}

Figure 2 shows the plantlets subjected to 1-6 $\mu \mathrm{M}$ ABA. Exposure to $4 \mu \mathrm{M}$ ABA was observed to result in the highest occurrence of hyperhydricity (Table 5). The leaves were translucent, with more green pigments than leaves formed in plantlets exposed to salinity stress. The plant's height increased significantly with increasing levels of ABA concentration until it reached $4 \mu \mathrm{M}$ ABA, at which point it started to decline significantly. However, the number of shoots and leaves were not significantly different throughout the ABA concentrations (Table 5). The leaves also showed an undulated margin (Figure 2). In addition, the multiplication index was also observed to be not significantly different throughout all ABA concentrations. 


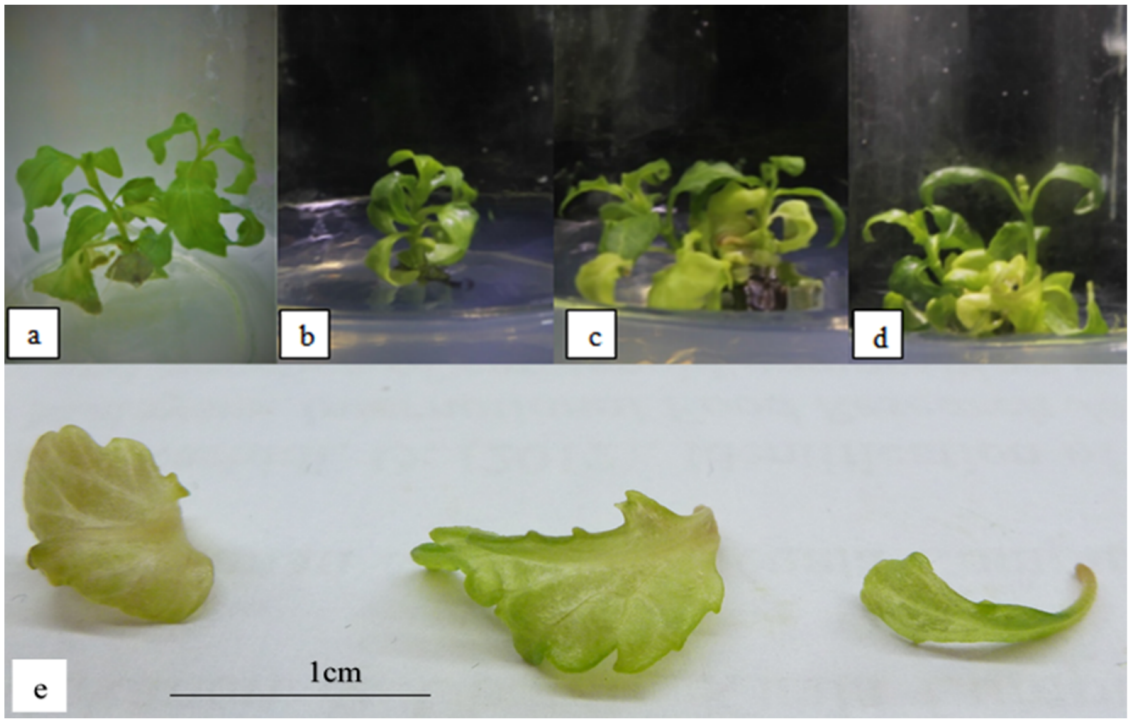

Figure 2. O. stamineus subjected to ABA stress harvested after the third subcultures: (a) $1 \mu \mathrm{M}$ ABA; (b) $2 \mu \mathrm{M} \mathrm{ABA}$; (c) $4 \mu \mathrm{M} \mathrm{ABA}$; (d) $6 \mu \mathrm{M} \mathrm{ABA}$; (e) hyperhydricity observed in leaves subjected to ABA stress.

\subsection{Morphology of Plantlets Exposed to High Kinetin Levels}

Figure 3 shows the plantlets subjected to $2.5,3.0,3.5$, and $4.0 \mathrm{mg} / \mathrm{L}$ kinetin. The occurrence of hyperhydricity was recorded to be the highest at $3.5 \mathrm{mg} / \mathrm{L}$ kinetin (Table 6). In terms of the morphology of the plantlets, the leaves were still visibly green in color, despite being translucent (Figure 3). This indicates that even if the leaves become hyperhydrated, they do not lose their pigments as a result of high cytokinin stress induced in the media. In addition, some of the leaves also showed underdeveloped serrated margins. Meanwhile, the height of the plantlets was observed to decrease significantly in treatments with $4.0 \mathrm{mg} / \mathrm{L}$ kinetin. However, no significant differences were observed in terms of the number of shoots and leaves produced, and the multiplication index after exposure to high kinetin concentrations.

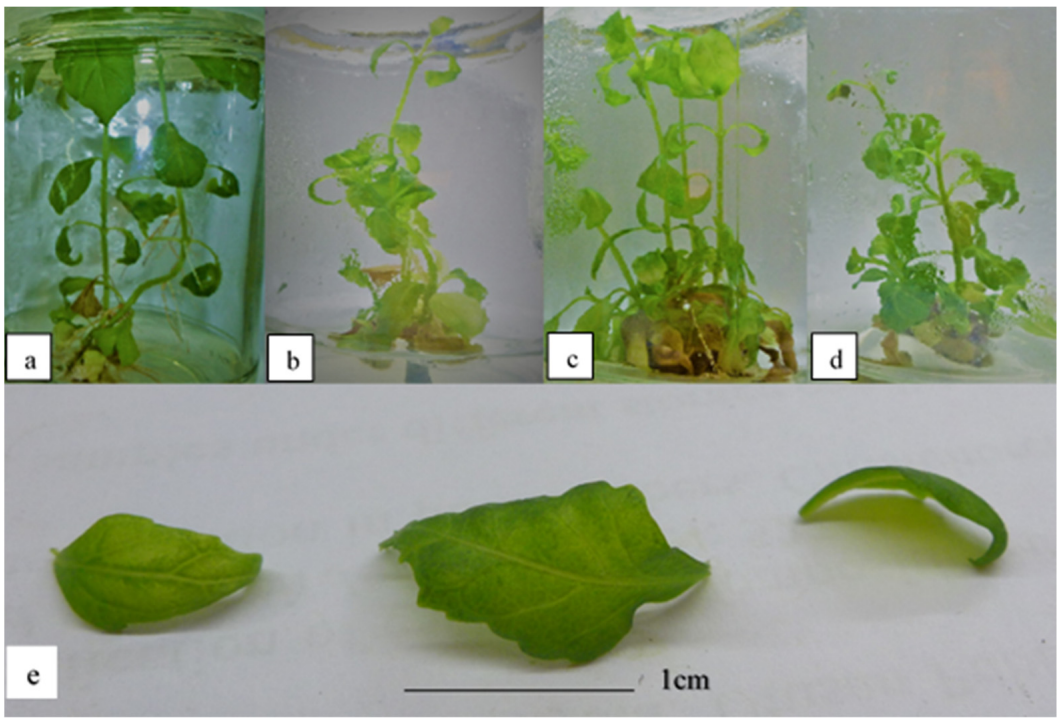

Figure 3. O. stamineus subjected to high kinetin levels harvested after the third subcultures: (a) $2.5 \mathrm{mg} / \mathrm{L}$ kinetin; (b) $3.0 \mathrm{mg} / \mathrm{L}$ kinetin; (c) $3.5 \mathrm{mg} / \mathrm{L}$ kinetin; (d) $4.0 \mathrm{mg} / \mathrm{L}$ kinetin; (e) hyperhydricity observed in leaves subjected to high kinetin levels. 


\subsection{ISSR-Based Genetic Stability Analysis of Stress-Induced Variants}

The leaves of the plantlets exposed to the abiotic stresses were harvested after the third subculture. DNA was extracted from all samples and used in the ISSR analysis to determine the genetic stability of the stress-induced plantlets as compared with the mother plant and that produced on optimum regeneration media (OM). To increase the accuracy of the results, four technical replicates were used for each treatment. In this study, 10 ISSR primers were used, similar to that used in previous genetic fidelity analysis of clonal regenerants [9].

Figure 4 depicts a gel image obtained from a PCR reaction conducted on plantlets exposed to high kinetin levels using the ISSR primer UBC855, which shows the presence of polymorphic and monomorphic bands. A total of 3452 scoreable bands were found in all of the samples examined (Table 7). The total number of bands amplified per primer ranged from 224 to 463 . The amplification range was between 300 and $2500 \mathrm{bp}$. Polymorphism was found in all primers. UBC 845 recorded the highest number of scoreable bands and the highest frequency of polymorphic bands $(86.54 \%)$, followed by UBC854 $(82.5 \%)$ and UBC807 26 (81.25\%), while UBC856 and UBC840 showed the lowest frequency of polymorphic bands per primer $(25 \%)$. Further details of the DNA bands amplified for each ISSR primer are listed in Table 7.

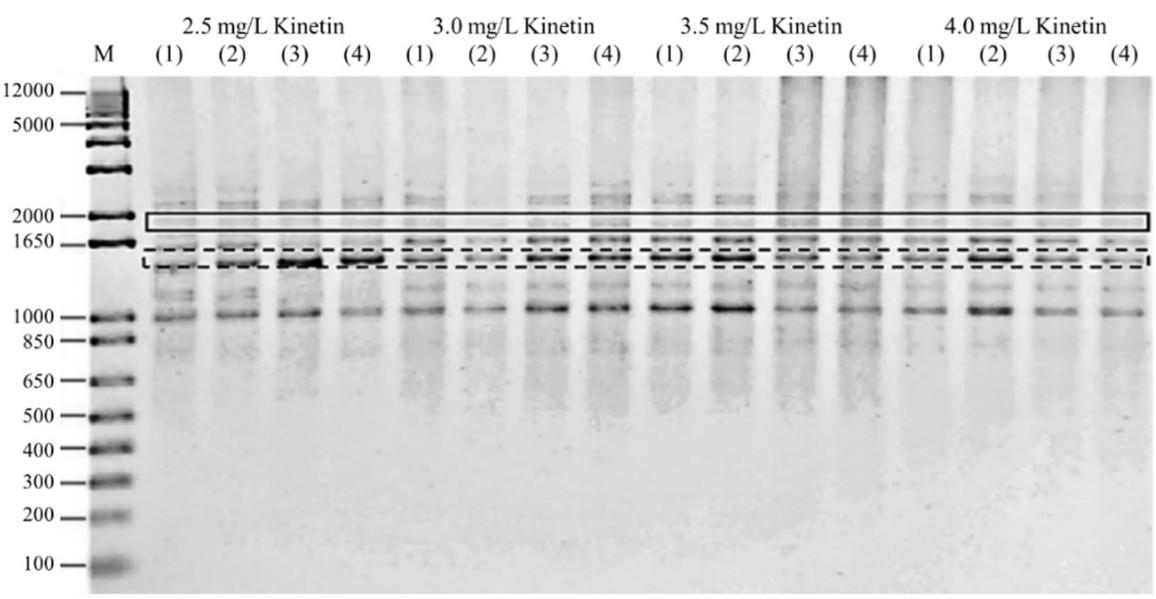

Figure 4. Gel image of PCR reaction on plantlets exposed to high cytokinin stress, obtained using ISSR primer UBC855. The polymorphic bands were highlighted using a solid line, while the monomorphic bands were shown using a dashed line.

Table 8 shows the Jaccard's distance coefficient table obtained from stress-induced plantlets, plantlets grown on MS0 and OM, as well as the mother plant. Using Darwin 6.0 software, the Jaccard's distance values were used to construct a phylogenetic tree to show the genetic distance between the somaclonal variants to the mother plant as well as clonal plantlets obtained on MS0 and OM. A cluster analysis was then, used to generate a UPGMA dendogram (Figure 5). The dendogram shows that the stress treatments were grouped together, while the mother plant, MSO, and OM were grouped together in a cluster. These observations further confirmed that the exposure to stress (salinity, ABA, and high kinetin) resulted in the formation of somaclonal variants that were genetically distant from the mother plant. 
Table 4. Effects of salt stress on mean number of shoots, multiplication index, leaves and roots per explant, mean percentage (\%) of explant producing callus, height and mean number of leaves showing vitrification (hyperhydricity) per explant.

\begin{tabular}{|c|c|c|c|c|c|c|c|}
\hline $\mathrm{OM}+\mathrm{NaCl}$ & $\begin{array}{l}\text { Mean No. of } \\
\text { Shoots per Explant }\end{array}$ & $\begin{array}{l}\text { Multiplication } \\
\text { Index }\end{array}$ & $\begin{array}{l}\text { Mean No. of Leaves } \\
\text { per Explant }\end{array}$ & $\begin{array}{l}\text { Mean No. of Roots } \\
\text { per Explant }\end{array}$ & Height $(\mathrm{cm})$ & $\begin{array}{l}\text { Mean No. of Leaves Showing } \\
\text { Hyperhydricity per Explant }\end{array}$ & $\begin{array}{l}\text { Mean \% of Explant } \\
\text { Producing Callus }\end{array}$ \\
\hline MS0 & $1.73 \pm 0.07^{\mathrm{d}}$ & $0.73 \pm 0.07^{c}$ & $13.91 \pm 0.38^{b}$ & $8.34 \pm 0.40^{a}$ & $7.65 \pm 0.26^{b}$ & $0.8 \pm 0.32^{b}$ & NR \\
\hline $\mathrm{OM}$ & $4.27 \pm 0.20^{\mathrm{a}}$ & $3.27 \pm 0.20^{\mathrm{a}}$ & $20.80 \pm 0.82^{a}$ & $8.47 \pm 0.83^{a}$ & $9.48 \pm 0.23^{a}$ & $1.8 \pm 0.55^{\mathrm{ab}}$ & $66.67 \pm 6.19^{a b}$ \\
\hline $0.001 \mathrm{mg} / \mathrm{L} \mathrm{NaCl}$ & $2.7 \pm 0.26^{c}$ & $1.80 \pm 0.23^{b}$ & $9.1 \pm 1.09^{c}$ & $0.59 \pm 0.19^{b}$ & $3.88 \pm 0.14^{c}$ & $2.93 \pm 0.61^{\mathrm{a}}$ & $73.33 \pm 5.81^{\mathrm{a}}$ \\
\hline $0.002 \mathrm{mg} / \mathrm{L} \mathrm{NaCl}$ & $3.36 \pm 0.24 b$ & $2.36 \pm 0.24^{b}$ & $8.54 \pm 0.62^{c}$ & $0.27 \pm 0.14^{b}$ & $3.28 \pm 0.10^{d}$ & $2.89 \pm 0.42^{\mathrm{a}}$ & $50.00 \pm 9.29^{c}$ \\
\hline $0.003 \mathrm{mg} / \mathrm{L} \mathrm{NaCl}$ & $2.86 \pm 0.23 b c$ & $1.89 \pm 0.22^{b}$ & $5.68 \pm 0.69^{d}$ & $0.10 \pm 0.07^{b}$ & $2.49 \pm 0.08^{\mathrm{e}}$ & $2.43 \pm 0.44^{\mathrm{a}}$ & $56.67 \pm 9.2^{b c}$ \\
\hline $0.004 \mathrm{mg} / \mathrm{L} \mathrm{NaCl}$ & $2.67 \pm 0.27^{c}$ & $1.80 \pm 0.23^{b}$ & $5.27 \pm 0.61^{\mathrm{d}}$ & $0.069 \pm 0.07^{b}$ & $2.07 \pm 0.07^{\mathrm{e}}$ & $2.33 \pm 0.54^{\mathrm{a}}$ & $65.52 \pm 8.68^{a b}$ \\
\hline
\end{tabular}

Data represent mean values \pm standard errors (SEs) with 30 explants in each treatment. Means with different letters within the same column are significantly different at $p<0.05$ according to Duncan's multiple range test (DMRT). NR, not recorded.

Table 5. Effects of ABA on mean number of shoots, multiplication index, leaves and roots per explant, mean percentage (\%) of explant producing callus, height and mean number of leaves showing vitrification (hyperhydricity) per explant.

\begin{tabular}{|c|c|c|c|c|c|c|c|}
\hline $\mathbf{O M}+\mathbf{A B A}$ & $\begin{array}{l}\text { Mean No. of } \\
\text { Shoots per Explant }\end{array}$ & $\begin{array}{l}\text { Multiplication } \\
\text { Index }\end{array}$ & $\begin{array}{l}\text { Mean No. of Leaves } \\
\text { per Explant }\end{array}$ & $\begin{array}{l}\text { Mean No. of Roots } \\
\text { per Explant }\end{array}$ & Height (cm) & $\begin{array}{l}\text { Mean No. of Leaves Showing } \\
\text { Hyperhydricity per Explant }\end{array}$ & $\begin{array}{l}\text { Mean \% of Explant } \\
\text { Producing Callus }\end{array}$ \\
\hline MS0 & $1.73 \pm 0.07^{b}$ & $0.73 \pm 0.07^{c}$ & $13.91 \pm 0.38^{\mathrm{b}}$ & $8.34 \pm 0.40^{\mathrm{a}}$ & $7.65 \pm 0.26^{b}$ & $0.8 \pm 0.32^{\mathrm{c}}$ & $\mathrm{NR}$ \\
\hline $\mathrm{OM}$ & $4.27 \pm 0.20^{\mathrm{a}}$ & $3.27 \pm 0.20^{\mathrm{a}}$ & $20.80 \pm 0.82^{a}$ & $8.47 \pm 0.83^{\mathrm{a}}$ & $9.48 \pm 0.23^{\mathrm{a}}$ & $1.8 \pm 0.55 \mathrm{bc}$ & $66.67 \pm 6.19^{\mathrm{a}}$ \\
\hline $1.0 \mu \mathrm{M}$ ABA & $2.23 \pm 0.18^{b}$ & $1.23 \pm 0.18^{b c}$ & $12.43 \pm 1.21^{\mathrm{b}}$ & $2.00 \pm 0.53^{b}$ & $5.04 \pm 0.09^{\mathrm{e}}$ & $1.3 \pm 0.34^{b c}$ & $6.67 \pm 4.63^{\mathrm{d}}$ \\
\hline $2.0 \mu \mathrm{M}$ ABA & $2.37 \pm 0.25^{b}$ & $1.47 \pm 0.22^{b}$ & $13.10 \pm 1.26^{b}$ & $0.23 \pm 0.10^{\mathrm{c}}$ & $5.95 \pm 0.13^{d}$ & $2.67 \pm 0.59 \mathrm{ab}$ & $50.00 \pm 9.29 \mathrm{ab}$ \\
\hline $4.0 \mu \mathrm{M}$ ABA & $2.37 \pm 0.25^{b}$ & $1.50 \pm 0.21^{b}$ & $13.0 \pm 1.63^{b}$ & $0.86 \pm 0.34^{b c}$ & $6.54 \pm 0.13^{c}$ & $4.08 \pm 0.91^{\mathrm{a}}$ & $27.59 \pm 8.16^{c}$ \\
\hline $6.0 \mu \mathrm{M}$ ABA & $2.33 \pm 0.28^{b}$ & $1.50 \pm 0.24^{b}$ & $12.23 \pm 1.74^{b}$ & $0.38 \pm 0.12^{\mathrm{c}}$ & $4.66 \pm 0.18^{\mathrm{e}}$ & $2.48 \pm 0.64 \mathrm{abc}$ & $3.33 \pm 7.32^{d}$ \\
\hline
\end{tabular}

Data represent mean values \pm standard errors (SEs) with 30 explants in each treatment. Means with different letters within the same column are significantly different at $p<0.05$ according to Duncan's multiple range test (DMRT). NR, not recorded. 
Table 6. Effects of high kinetin levels on mean number of shoots, multiplication index, leaves and roots per explant, mean percentage (\%) of explant producing callus, height and mean number of leaves showing hyperhydricity (vitrification) per explant.

\begin{tabular}{|c|c|c|c|c|c|c|c|}
\hline $\begin{array}{l}\text { OM + Kinetin } \\
\text { (Kin) }\end{array}$ & $\begin{array}{c}\text { Mean No. of } \\
\text { Shoots per Explant }\end{array}$ & $\begin{array}{l}\text { Multiplication } \\
\text { Index }\end{array}$ & $\begin{array}{l}\text { Mean No. of Leaves } \\
\text { per Explant }\end{array}$ & $\begin{array}{l}\text { Mean No. of Roots } \\
\text { per Explant }\end{array}$ & Height (cm) & $\begin{array}{l}\text { Mean No. of Leaves Showing } \\
\text { Hyperhydricity per Explant }\end{array}$ & $\begin{array}{l}\text { Mean \% of Explant } \\
\text { Producing Callus }\end{array}$ \\
\hline MS0 & $1.73 \pm 0.07^{c}$ & $0.73 \pm 0.07^{b}$ & $13.91 \pm 0.38^{b}$ & $8.34 \pm 0.40^{a}$ & $7.65 \pm 0.26^{b}$ & $0.80 \pm 0.32^{c}$ & NR \\
\hline $\mathrm{OM}$ & $4.27 \pm 0.20^{\mathrm{ab}}$ & $3.27 \pm 0.20^{a}$ & $20.80 \pm 0.82^{a}$ & $8.47 \pm 0.83^{a}$ & $9.48 \pm 0.23^{a}$ & $1.80 \pm 0.55^{b c}$ & $66.67 \pm 6.19^{c}$ \\
\hline $3.0 \mathrm{mg} / \mathrm{L} \mathrm{Kin}$ & $4.33 \pm 0.37^{\mathrm{ab}}$ & $3.40 \pm 0.35^{\mathrm{a}}$ & $15.2 \pm 1.35^{b}$ & $0.40 \pm 0.18^{b}$ & $7.49 \pm 0.08^{b c}$ & $3.80 \pm 0.89 \mathrm{ab}$ & $86.67 \pm 6.31^{b}$ \\
\hline $3.5 \mathrm{mg} / \mathrm{L} \mathrm{Kin}$ & $4.72 \pm 0.39^{\mathrm{a}}$ & $3.72 \pm 0.39^{a}$ & $16.62 \pm 1.23^{b}$ & $0.14 \pm 0.08^{b}$ & $7.26 \pm 0.17^{b c}$ & $6.28 \pm 0.84^{\mathrm{a}}$ & $93.10 \pm 4.63^{\mathrm{a}}$ \\
\hline $4.0 \mathrm{mg} / \mathrm{L} \mathrm{Kin}$ & $4.31 \pm 0.34^{\mathrm{ab}}$ & $3.31 \pm 0.34^{\mathrm{a}}$ & $15.79 \pm 1.31^{b}$ & $0.27 \pm 0.14^{b}$ & $6.98 \pm 0.14^{c}$ & $4.66 \pm 0.75^{\mathrm{ab}}$ & $76.67 \pm 7.85^{b c}$ \\
\hline
\end{tabular}

Data represent mean values \pm standard errors (SEs) with 30 explants in each treatment. Means with different letters within the same column are significantly different at $p<0.05$ according to Duncan's multiple range test (DMRT). NR, not recorded.

Table 7. Primers used in the ISSR polymorphism analysis, number and size of amplified fragments of Orthosiphon stamineus plantlets exposed to abiotic stress.

\begin{tabular}{|c|c|c|c|c|c|c|}
\hline Primer Code (UBC) & Sequence $5^{\prime}-3^{\prime}$ & $\begin{array}{l}\text { Annealing Temperature } \\
\left({ }^{\circ} \mathrm{C}\right)\end{array}$ & $\begin{array}{c}\text { Total Number of Bands } \\
\text { Amplified }\end{array}$ & $\begin{array}{l}\text { Number of Scorable } \\
\text { Bands per Primer }\end{array}$ & $\begin{array}{l}\text { Number and Frequency of } \\
\text { Polymorphic Bands per Primer }\end{array}$ & $\begin{array}{c}\text { Range of Amplification } \\
\text { (bp) }\end{array}$ \\
\hline UBC807 & $(\mathrm{AG})_{8} \mathrm{~T}$ & 46.5 & 283 & $8(32)$ & $26(81.25 \%)$ & 500-2000 \\
\hline UBC829 & $(\mathrm{TG})_{8} \mathrm{C}$ & 52.5 & 382 & $8(32)$ & $20(62.5 \%)$ & $600-1300$ \\
\hline UBC836 & $(\mathrm{AG})_{8} \mathrm{YA}$ & 48.0 & 415 & $11(44)$ & $32(72.73 \%)$ & $400-2300$ \\
\hline UBC 840 & $(\mathrm{GA})_{8} \mathrm{YT}$ & 46.5 & 301 & $6(24)$ & $6(25 \%)$ & $300-1300$ \\
\hline UBC 841 & $(\mathrm{GA})_{8} \mathrm{YC}$ & 52.0 & 224 & $5(20)$ & $13(65 \%)$ & $400-2500$ \\
\hline UBC 845 & $(\mathrm{CT})_{8} \mathrm{RG}$ & 47.5 & 419 & $13(52)$ & $45(86.54 \%)$ & $400-1800$ \\
\hline UBC855 & $(\mathrm{AC})_{8} \mathrm{YT}$ & 53.0 & 463 & $10(40)$ & $31(77.5 \%)$ & $400-2000$ \\
\hline UBC856 & $(\mathrm{AC})_{8} \mathrm{YA}$ & 54.0 & 228 & $4(16)$ & $4(25 \%)$ & $700-1500$ \\
\hline Total & & & 3452 & $82(328)$ & $230(70.12 \%)$ & \\
\hline
\end{tabular}


Table 8. Genetic distance based on Jaccard's distance coefficient for in vitro grown O. stamineus plantlets exposed to abiotic stress.

\begin{tabular}{|c|c|c|c|c|c|c|c|c|c|c|c|c|c|c|c|}
\hline & & \multirow{2}{*}{ In Vivo } & \multirow{2}{*}{ MS0 } & \multirow{2}{*}{ OM } & \multicolumn{4}{|c|}{$\mathrm{ABA}(\mu \mathrm{M})$} & \multicolumn{4}{|c|}{ Kinetin (mg/L) } & \multicolumn{3}{|c|}{$\mathrm{NaCl}$ (mg/L) } \\
\hline & & & & & 1.0 & 2.0 & 4.0 & 6.0 & 2.5 & 3.0 & 3.5 & 4.0 & 0.001 & 0.002 & 0.003 \\
\hline \multirow{2}{*}{\multicolumn{2}{|c|}{$\begin{array}{l}\text { MS0 } \\
\text { OM }\end{array}$}} & 0.103370 & & & & & & & & & & & & & \\
\hline & & 0.103370 & 0.103370 & & & & & & & & & & & & \\
\hline \multirow{4}{*}{$\begin{array}{l}\text { ABA } \\
(\mu \mathrm{M})\end{array}$} & 1.0 & 0.562741 & 0.562741 & 0.562741 & & & & & & & & & & & \\
\hline & 2.0 & 0.562741 & 0.562741 & 0.562741 & 0.187652 & & & & & & & & & & \\
\hline & 4.0 & 0.562741 & 0.562741 & 0.562741 & 0.187652 & 0.187652 & & & & & & & & & \\
\hline & 6.0 & 0.562741 & 0.562741 & 0.562741 & 0.187652 & 0.187652 & 0.103370 & & & & & & & & \\
\hline \multirow{4}{*}{$\begin{array}{l}\text { Kinetin } \\
(\mathrm{mg} / \mathrm{L})\end{array}$} & 2.5 & 0.562741 & 0.562741 & 0.562741 & 0.562741 & 0.562741 & 0.562741 & 0.562741 & & & & & & & \\
\hline & 3.0 & 0.562741 & 0.562741 & 0.562741 & 0.562741 & 0.562741 & 0.562741 & 0.562741 & 0.103370 & & & & & & \\
\hline & 3.5 & 0.562741 & 0.562741 & 0.562741 & 0.562741 & 0.562741 & 0.562741 & 0.562741 & 0.103370 & 0.103370 & & & & & \\
\hline & 4.0 & 0.562741 & 0.562741 & 0.562741 & 0.562741 & 0.562741 & 0.562741 & 0.562741 & 0.103370 & 0.103370 & 0.103370 & & & & \\
\hline \multirow{4}{*}{$\begin{array}{c}\mathrm{NaCl} \\
(\mathrm{mg} / \mathrm{L})\end{array}$} & 0.001 & 0.562741 & 0.562741 & 0.562741 & 0.562741 & 0.562741 & 0.562741 & 0.562741 & 0.562741 & 0.562741 & 0.562741 & 0.562741 & & & \\
\hline & 0.002 & 0.562741 & 0.562741 & 0.562741 & 0.562741 & 0.562741 & 0.562741 & 0.562741 & 0.562741 & 0.562741 & 0.562741 & 0.562741 & 0.187652 & & \\
\hline & 0.003 & 0.562741 & 0.562741 & 0.562741 & 0.562741 & 0.562741 & 0.562741 & 0.562741 & 0.562741 & 0.562741 & 0.562741 & 0.562741 & 0.187652 & 0.187652 & \\
\hline & 0.004 & 0.562741 & 0.562741 & 0.562741 & 0.562741 & 0.562741 & 0.562741 & 0.562741 & 0.562741 & 0.562741 & 0.562741 & 0.562741 & 0.187652 & 0.187652 & 0.187652 \\
\hline
\end{tabular}

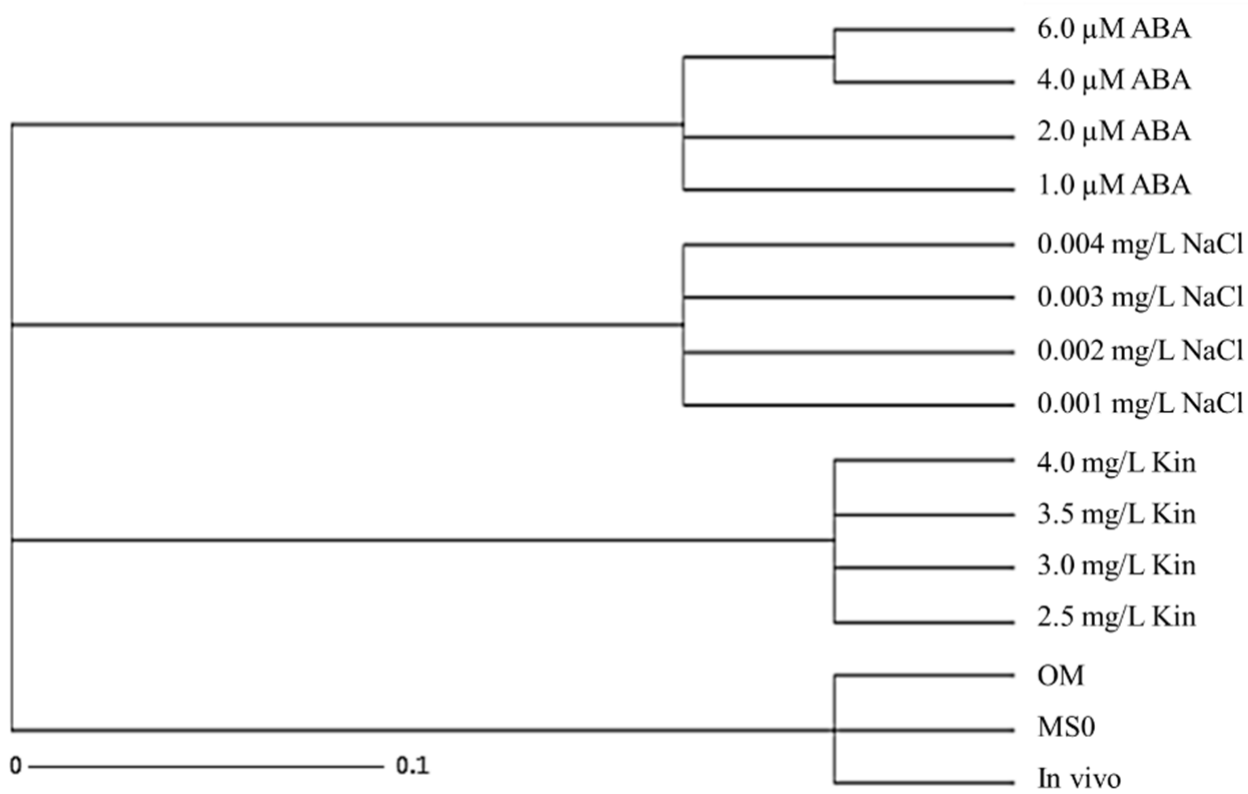

Figure 5. Phylogenetic tress constructed for plantlets exposed to various abiotic stresses as compared with the mother plant (in vivo), MS basal (MS0) and optimum media (OM).

\subsection{Physiological and Biochemical Analysis}

\subsubsection{Chlorophyll Content}

As shown in Figure 6, it can be observed that the content of chlorophyll $b$ was higher than chlorophyll a in all the treatments given. Figure 6a only shows the data for $0.001 \mathrm{mg} / \mathrm{L}$ $\mathrm{NaCl}$, because, for plants grown at higher salinity level, the leaf sizes were too small and were not able to be used for chlorophyll content estimation. Generally, all plants treated with ABA exhibited low chlorophyll content (Figure $6 \mathrm{~b}$ ), while high kinetin levels induced higher chlorophyll content, but was dropped drastically in $3.5 \mathrm{mg} / \mathrm{L}$ kinetin (Figure 6c).

As observed from Figure 7a, the ratio of chlorophyll a to chlorophyll $b$ produced under $0.001 \mathrm{mg} / \mathrm{L} \mathrm{NaCl}$ was higher than in plants grown on OM and MSO. A decreasing pattern can be observed in the ratio of chlorophyll a to chlorophyll $\mathrm{b}$ produced in O. stamineus plants exposed to ABA stress (Figure $7 \mathrm{~b}$ ). Meanwhile, in plants subjected to high cytokinin stress (Figure 7c), the ratio of chlorophyll a to chlorophyll b was observed to increase drastically when the concentration of kinetin was increased from 2.0 to $2.5 \mathrm{mg} / \mathrm{L}$ kinetin. The ratio of chlorophyll a to chlorophyll b was also observed to peak at $3.5 \mathrm{mg} / \mathrm{L}$ kinetin and dropped at $4.0 \mathrm{mg} / \mathrm{L}$ kinetin. 
(a)

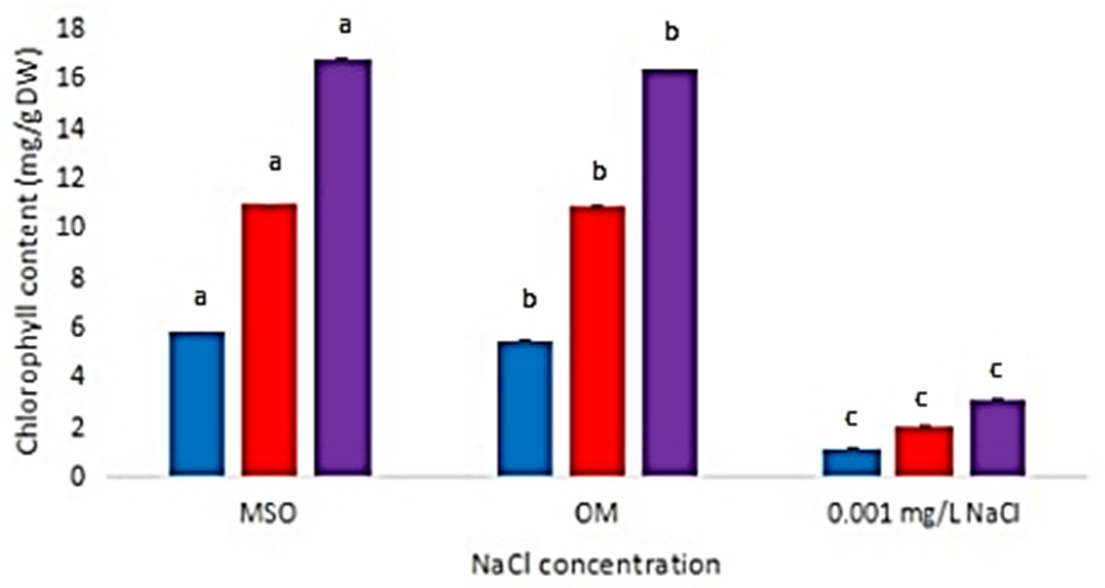

Q Chlorophyll a G Chlorophyll b $\mathbf{a}$ Chlorophyl a+b

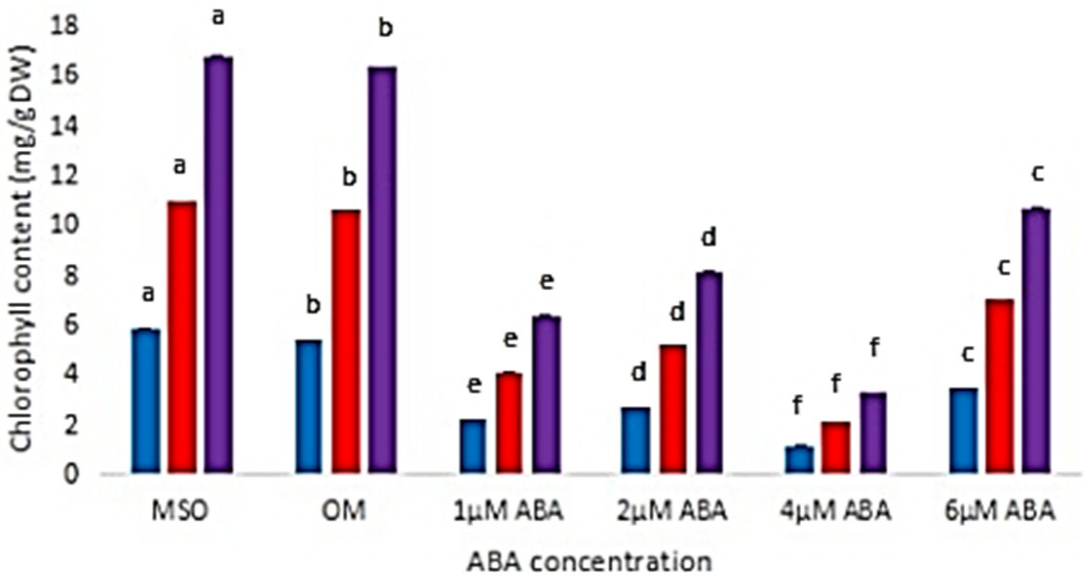

a Chlorophyll a $\mathbf{E}$ Chlorophyll b $\mathbf{a}$ Chlorophyl a+b

(b)

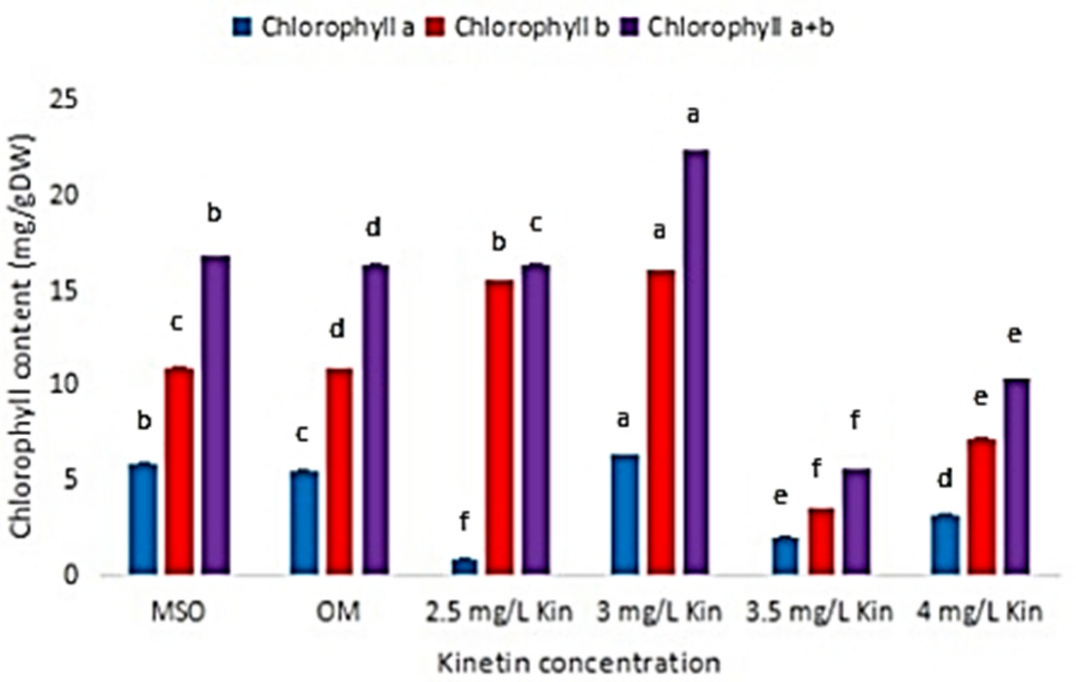

a Chlorophyll a Chlorophyll b a Chlorophyll a+b

Figure 6. Chlorophyll content in plants exposed to: (a) salt stress $(0.001 \mathrm{mg} / \mathrm{L} \mathrm{NaCl})$; (b) ABA; (c) high kinetin levels. Means with different letters are significantly different at $p<0.05$ according to Duncan's multiple range test (DMRT), subject to different type of measurement conducted. 
(a)

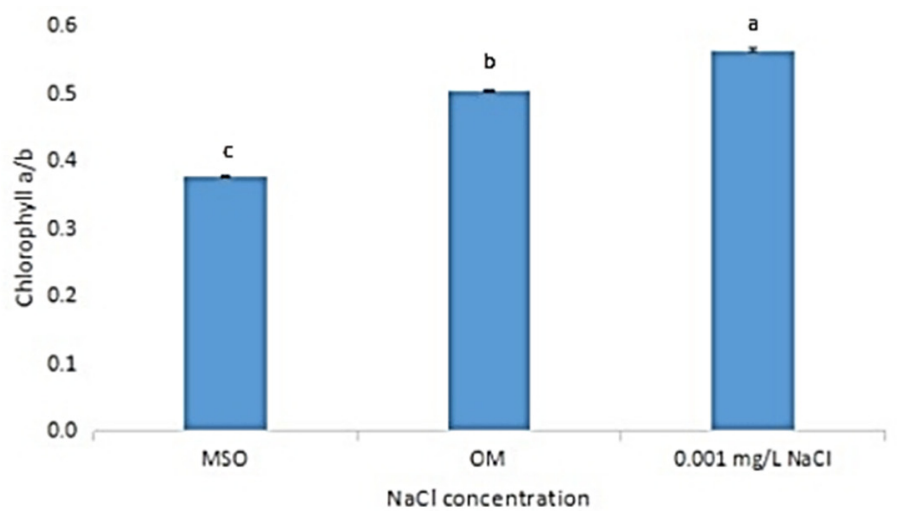

(b)

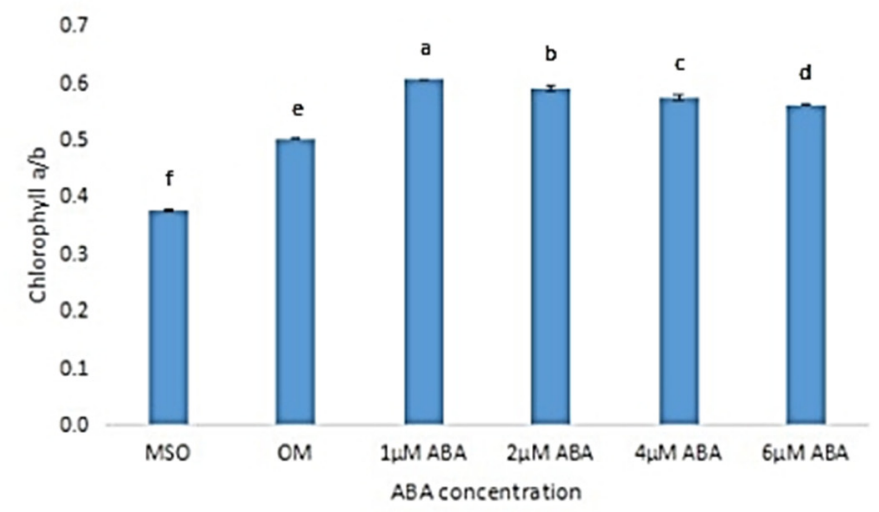

(c)

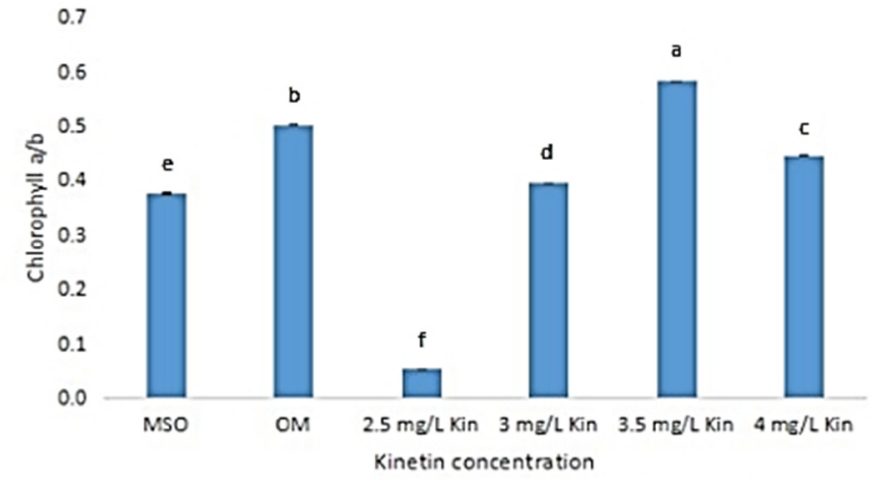

Figure 7. Ratio of chlorophyll a to chlorophyll $\mathrm{b}$ in plants exposed to: (a) salt stress $(0.001 \mathrm{mg} / \mathrm{L}$ $\mathrm{NaCl}$ ); (b) ABA; (c) high kinetin levels. Means with different letters are significantly different at $p<0.05$ according to Duncan's multiple range test (DMRT).

Based on Figure 8, the leaves from plants grown on OM had the highest SPAD values $(34.00 \pm 2.55)$ followed by MS0 $(22.00 \pm 2.00)$. In plants exposed to salinity stress, the SPAD value was observed to decrease as the concentration of $\mathrm{NaCl}$ decreased (Figure 8a). In comparison, plants treated with ABA were observed to exhibit a significantly lower SPAD value than that recorded by plants grown on MS0 and OM. However, the increase in ABA concentration was found to be insignificant in influencing the SPAD values of the plants, where similar SPAD values were recorded across all ABA concentrations (Figure 8b). Meanwhile, the exposure to high kinetin levels resulted in a significant decrease in SPAD values when the kinetin concentration was increased from $2.0 \mathrm{mg} / \mathrm{L}(\mathrm{OM})$ to $2.5 \mathrm{mg} / \mathrm{L}$ (Figure $8 \mathrm{c}$ ). The SPAD value was also observed to decrease further when the kinetin concentration was increased to $3.0 \mathrm{mg} / \mathrm{L}$. Nevertheless, further increase in kinetin concentration was observed to yield non-significant differences in the SPAD values. 
(a)

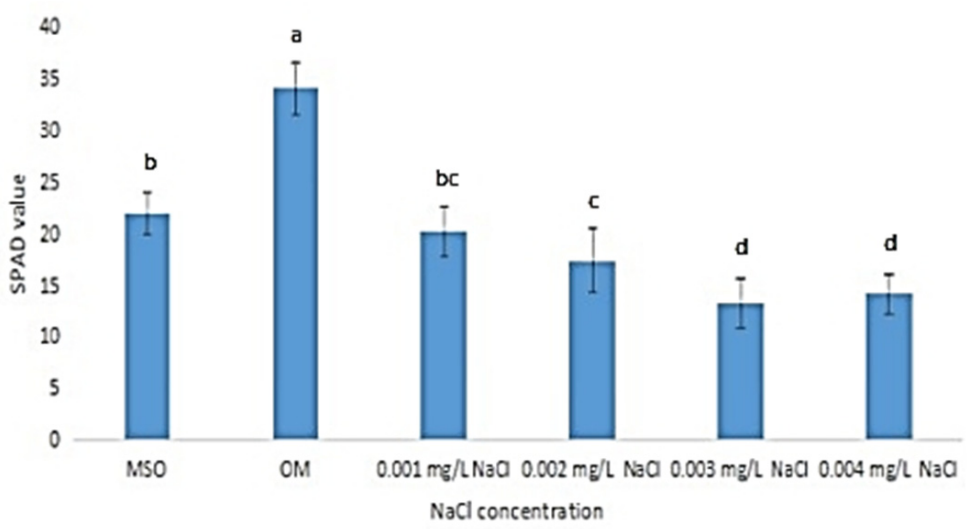

(b)

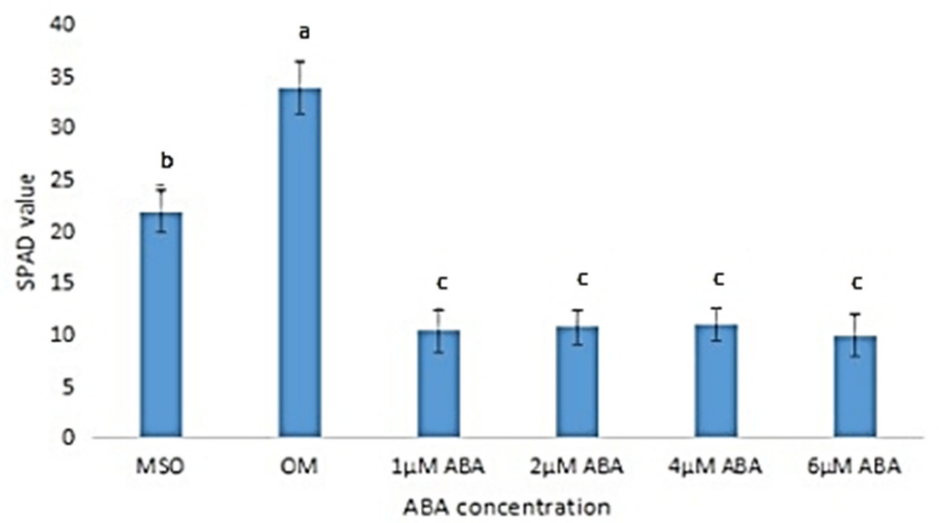

(c)

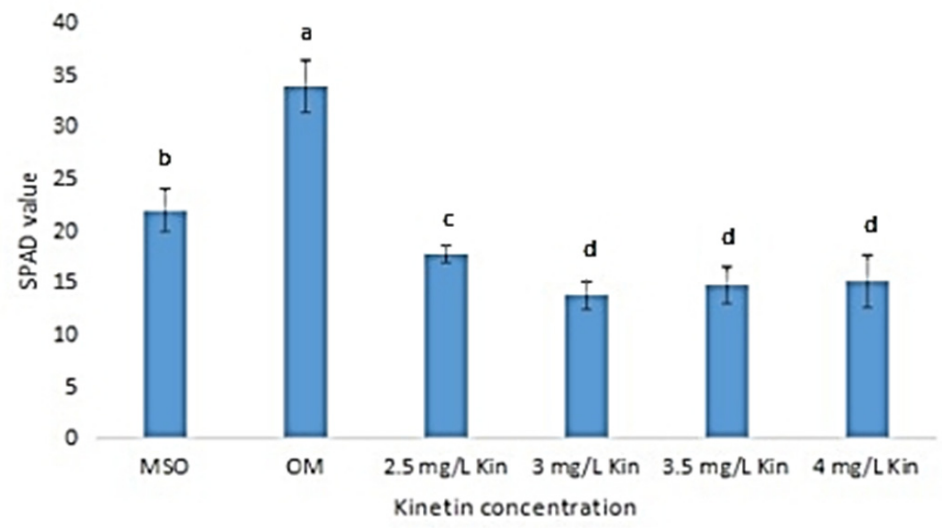

Figure 8. SPAD values in plants exposed to: (a) salt stress; (b) ABA; (c) high kinetin levels. Means with different letters are significantly different at $p<0.05$ according to Duncan's multiple range test (DMRT).

\subsubsection{Malondialdehyde (MDA) Content}

The malondialdehyde (MDA) mean values in the plantlets exposed to abiotic stresses showed a steady increase as the stress levels increased, as shown in Figure 9. Plantlets grown on MS0 and OM exhibited significantly lower MDA levels than plantlets exposed to all abiotic stress treatments. The MDA levels were observed to increase when the plantlets were exposed to salinity, ABA, and high kinetin levels. Nevertheless, when the salt $(\mathrm{NaCl})$ concentration was increased to $0.001 \mathrm{mg} / \mathrm{L}$, the increase in MDA level was insignificant (Figure 9a). Meanwhile, the MDA levels were observed to plateau when the plantlets were exposed to ABA concentrations above $2 \mu \mathrm{M}$ (Figure 9b). 
(a)

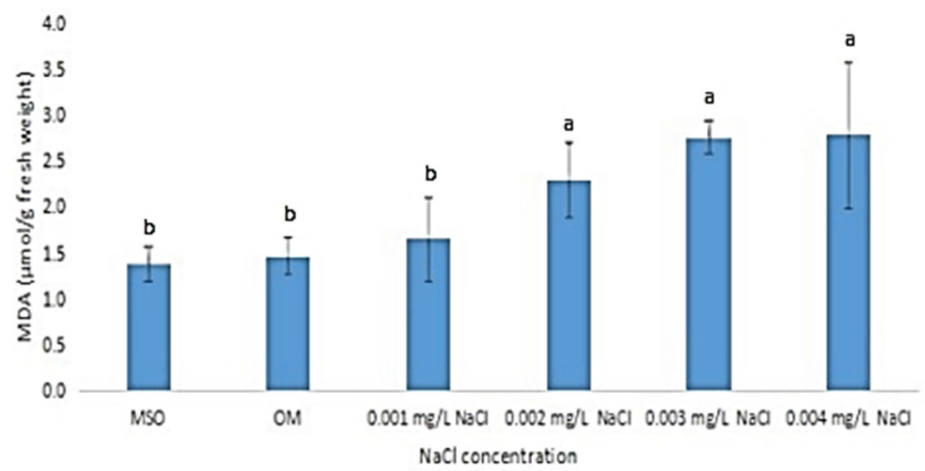

(b)

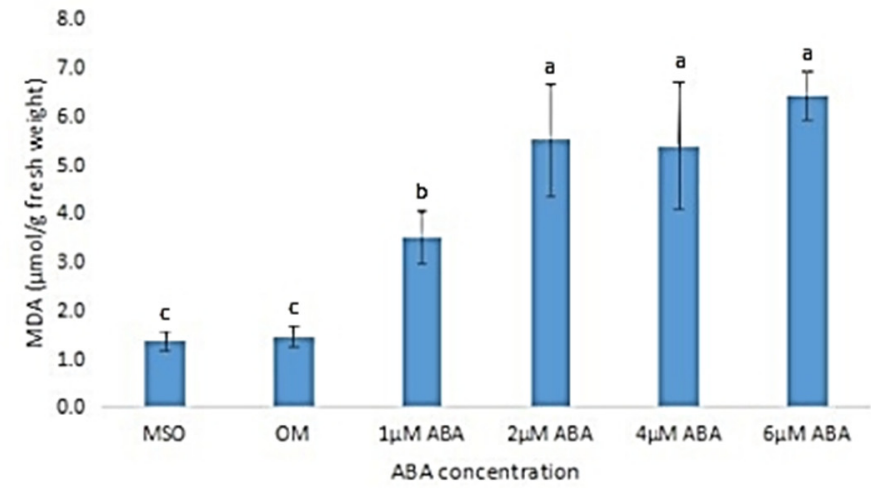

(c)

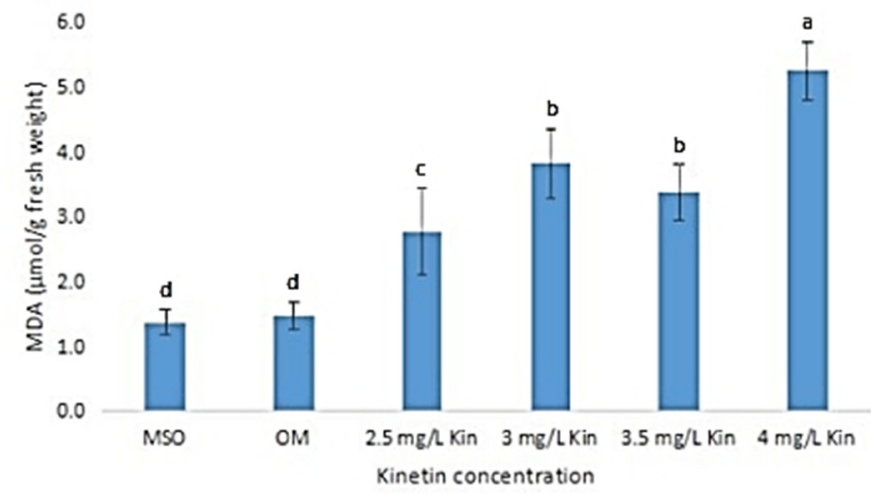

Figure 9. MDA levels of plants exposed to: (a) salt stress; (b) ABA; (c) high kinetin levels. Means with different letters are significantly different at $p<0.05$ according to Duncan's multiple range test (DMRT).

\subsubsection{Net Photosynthesis}

According to Figure 10, the net photosynthesis of the plantlets decreased with the increase in stress concentrations. Plants grown on MS0 showed the highest net photosynthesis, followed by plants grown on OM. Figure 10a shows that the exposure to salinity stress caused a reduction in the plant's net photosynthesis activity, and continued to decrease further when the $\mathrm{NaCl}$ concentrations were increased. Nevertheless, reductions in the net photosynthesis activities were found to be not significant at $\mathrm{NaCl}$ concentrations of $0.002 \mathrm{mg} / \mathrm{L}$ and $0.003 \mathrm{mg} / \mathrm{L}$. Similar observations were also recorded in plantlets exposed to $\mathrm{ABA}$, where the net photosynthesis significantly decreased upon exposure to $\mathrm{ABA}$ as compared with that observed in plantlets grown on MS0 and OM. Exposure to ABA at concentrations higher than $2 \mu \mathrm{M}$ was found to yield insignificant changes in the net photosynthesis levels (Figure 10b). The same trend was observed in plantlets exposed to high kinetin levels with that observed in ABA treatments (Figure 10c). 
(a)

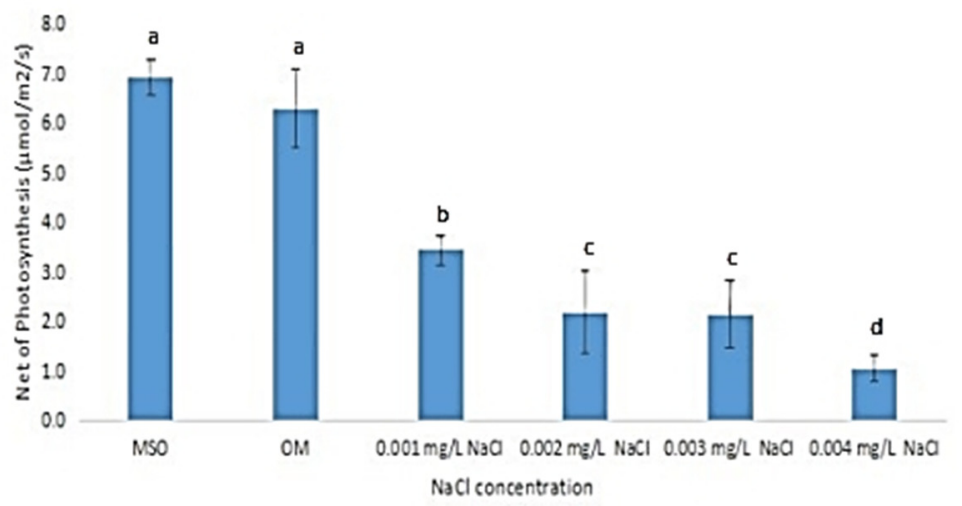

(b)

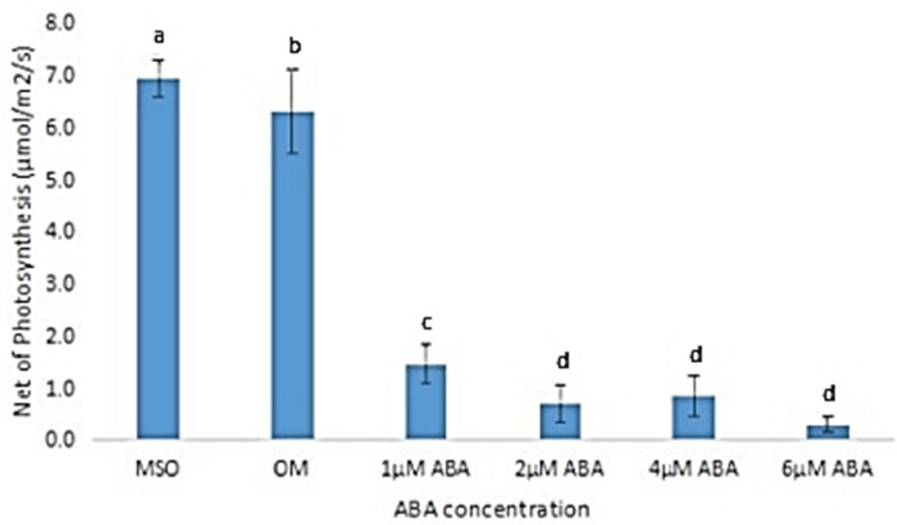

(c)

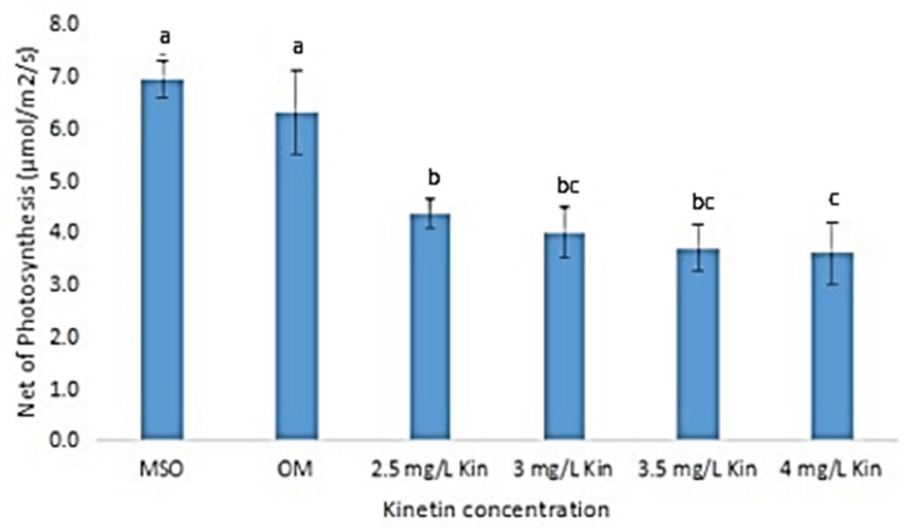

Figure 10. Net photosynthesis of plants exposed to: (a) salt stress; (b) ABA; (c) high kinetin levels. Means with different letters are significantly different at $p<0.05$ according to Duncan's multiple range test (DMRT).

\subsubsection{Transpiration}

The transpiration rates of the plantlets were observed to exhibit the same pattern as that observed in net photosynthesis, whereby, the rate of transpiration decreased as the stress concentrations increased. OM recorded the highest transpiration rate $\left(2.34 \pm 0.21 \mathrm{mmol} / \mathrm{m}^{2} / \mathrm{s}\right)$ which was significantly higher than all treatments, followed by MS0 $\left(1.75 \pm 0.43 \mathrm{mmol} / \mathrm{m}^{2} / \mathrm{s}\right)$. The transpiration rates of the plants grown under salinity stress decreased significantly from $1.43 \pm 0.23 \mathrm{mmol} / \mathrm{m}^{2} / \mathrm{s}$, in plants exposed to $0.001 \mathrm{mg} / \mathrm{L} \mathrm{NaCl}$, to $0.14 \pm 0.04 \mathrm{mmol} / \mathrm{m}^{2} / \mathrm{s}$, in plants exposed to $0.004 \mathrm{mg} / \mathrm{L} \mathrm{NaCl}$ (Figure 11a). The transpiration rates of plants under ABA stress also exhibited the same pattern, which showed a significant decrease from $1 \mu \mathrm{M}$ $\mathrm{ABA}$ to $2 \mu \mathrm{M} \mathrm{ABA}$, but showed insignificant changes when the ABA levels were further increased, up to $6 \mu \mathrm{M}$ (Figure 11b). 
(a)

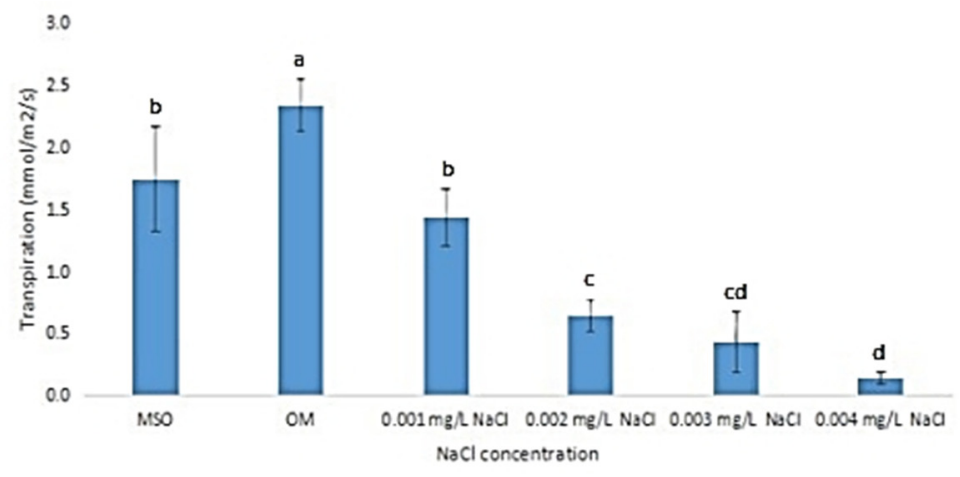

(b)

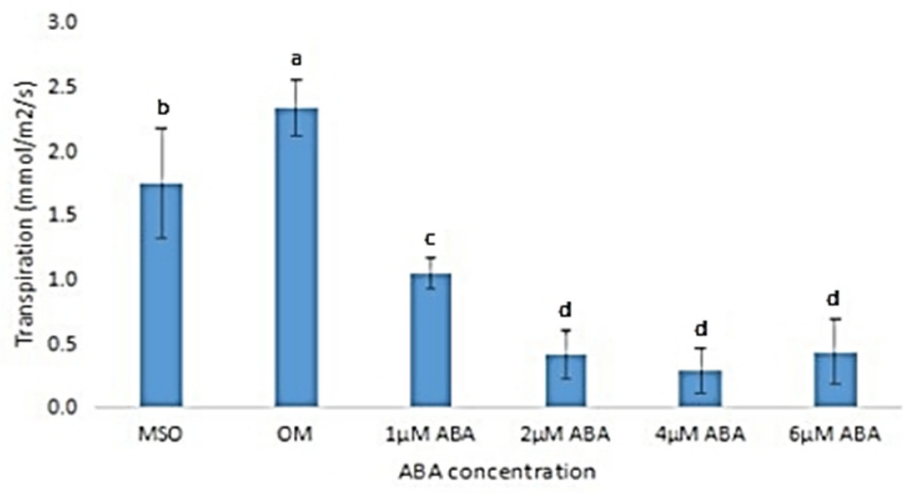

(c)

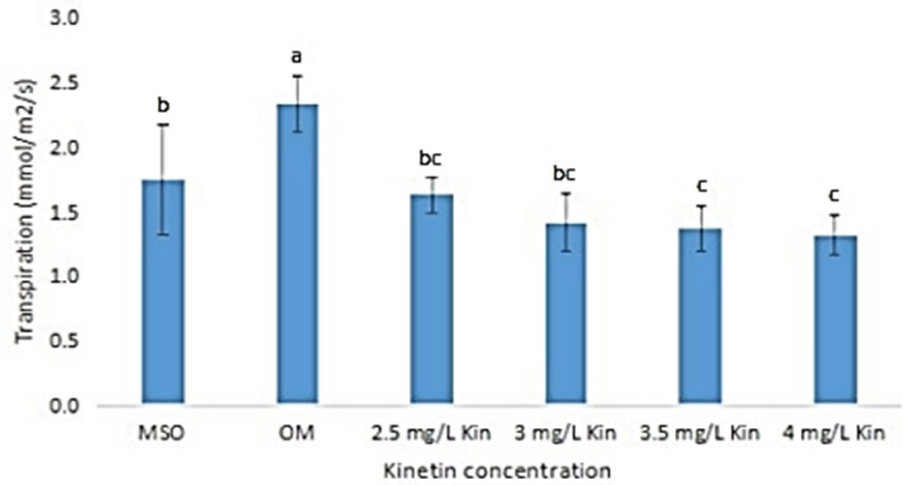

Figure 11. Transpiration rate of plants exposed to: (a) salt stress; (b) ABA; (c) high kinetin levels. Means with different letters are significantly different at $p<0.05$ according to Duncan's multiple range test (DMRT).

On the other hand, the plantlets grown with the lowest kinetin concentration $(2.0 \mathrm{mg} / \mathrm{L}$, $\mathrm{OM}$ ) showed the highest transpiration rate as compared with other kinetin concentrations (Figure 11c). When the kinetin concentration was increased to $2.5 \mathrm{mg} / \mathrm{L}$ kinetin, the rate of transpiration decreased significantly, then, the rate of transpiration decreased further when the concentration was increased to $4.0 \mathrm{mg} / \mathrm{L}$ kinetin (Figure 11c). Nevertheless, the decrease in the transpiration rate was observed to be insignificant.

\subsubsection{Stomatal Conductance}

Plants grown on OM and MS0 showed significantly higher stomatal conductance than all samples exposed to abiotic stresses $\left(0.31 \pm 0.06 \mathrm{~mol} / \mathrm{m}^{2} / \mathrm{s}\right)$. Different $\mathrm{NaCl}$ concentrations did not have a significant influence on stomatal conductance of the plantlets (Figure 12a). In the treatments with $\mathrm{ABA}$, exposure to $2 \mu \mathrm{M}$ ABA was observed to result in the highest stomatal conductance $\left(0.13 \pm 0.03 \mathrm{~mol} / \mathrm{m}^{2} / \mathrm{s}\right)$ as compared with other $\mathrm{ABA}$ concentrations (Figure 12b). Similar observations were recorded in high cytokinin treatments, 
where the stomatal conductance was observed to decrease when the concentrations of kinetin were decreased from $2.0 \mathrm{mg} / \mathrm{L}(\mathrm{OM})$ to $3.0 \mathrm{mg} / \mathrm{L}$. However, subsequent increases in ABA concentrations yielded an insignificant change of stomatal conductance of the plantlets (Figure 12c).

(a)

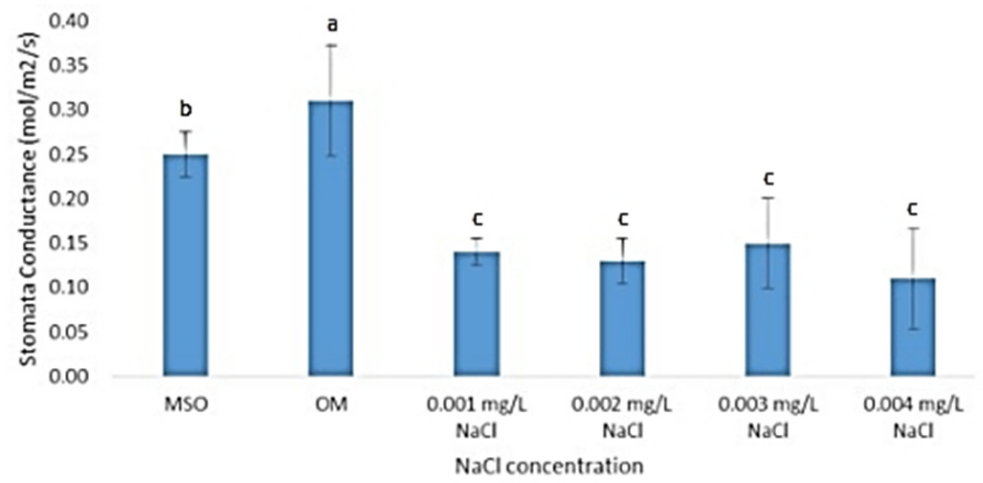

(b)

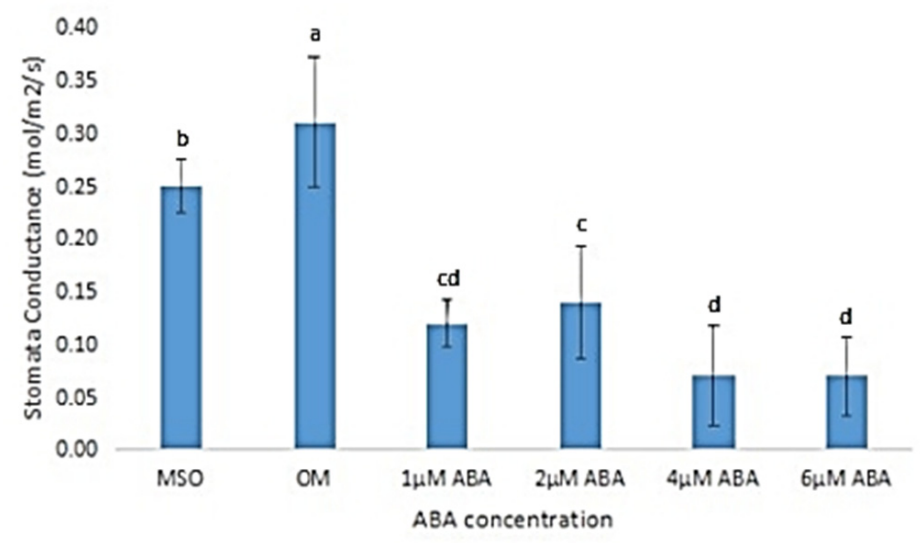

(c)

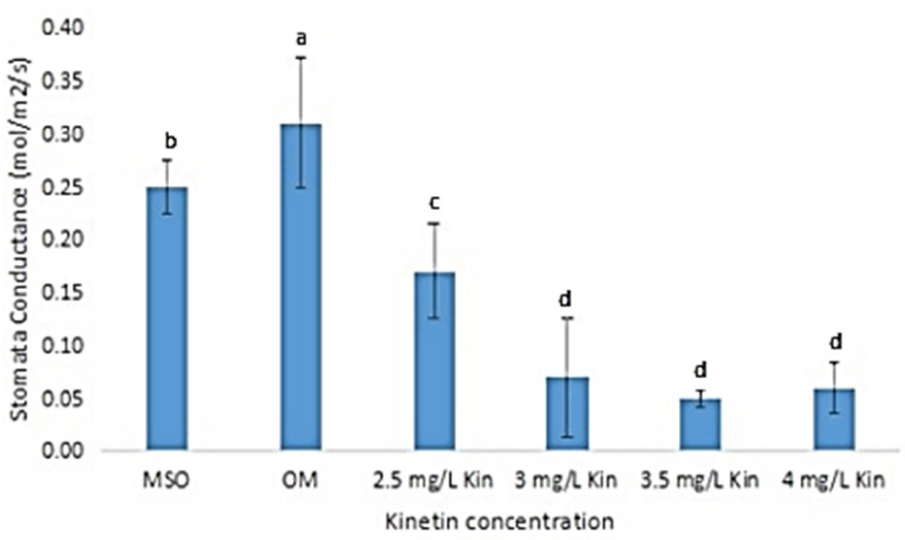

Figure 12. Stomatal conductance of plants exposed to: (a) salt stress; (b) ABA; (c) high kinetin levels. Means with different letters are significantly different at $p<0.05$ according to Duncan's multiple range test (DMRT).

\subsubsection{Water Use Efficiency}

The mean water use efficiency (WUE) was observed to be higher in plantlets grown on MS0 than that of plantlets grown on OM (Figure 13). Exposure to high salinity (at $0.003 \mathrm{mg} / \mathrm{L} \mathrm{NaCl}$ and higher) was observed to result in an increase in the WUE of the samples (Figure 13a). In contrast, both ABA and high kinetin treatments were observed to cause a reduction in WUE of the plantlets as compared with that produced by plantlets 
grown on MS0, however, subsequent increases in the ABA and kinetin concentrations were found to yield insignificant changes in the WUE of the samples (Figure 13b,c).

(a)

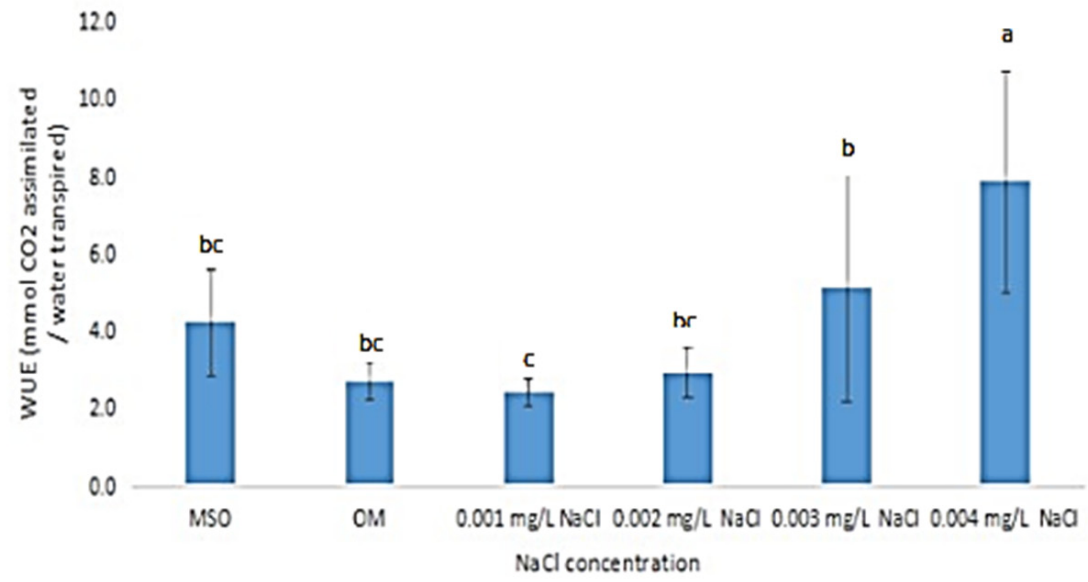

(b)

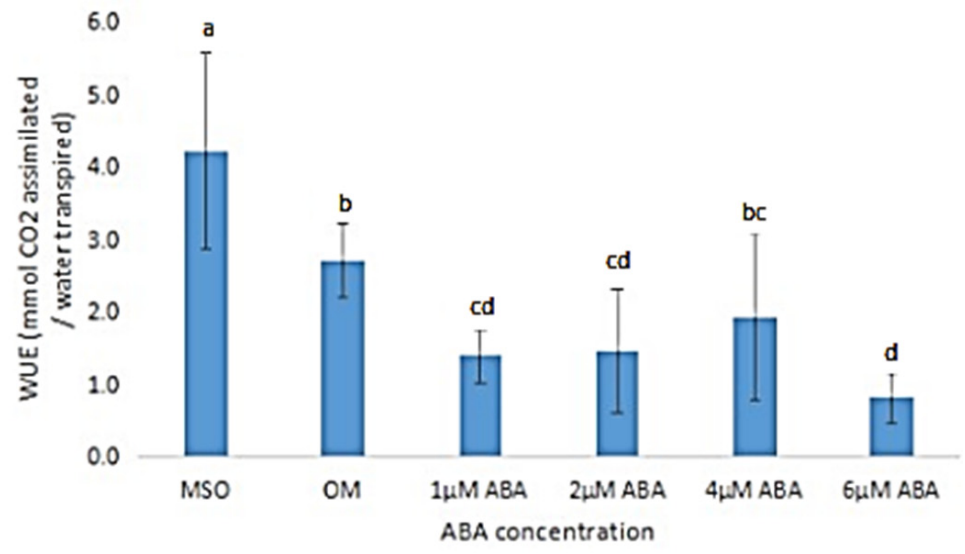

(c)

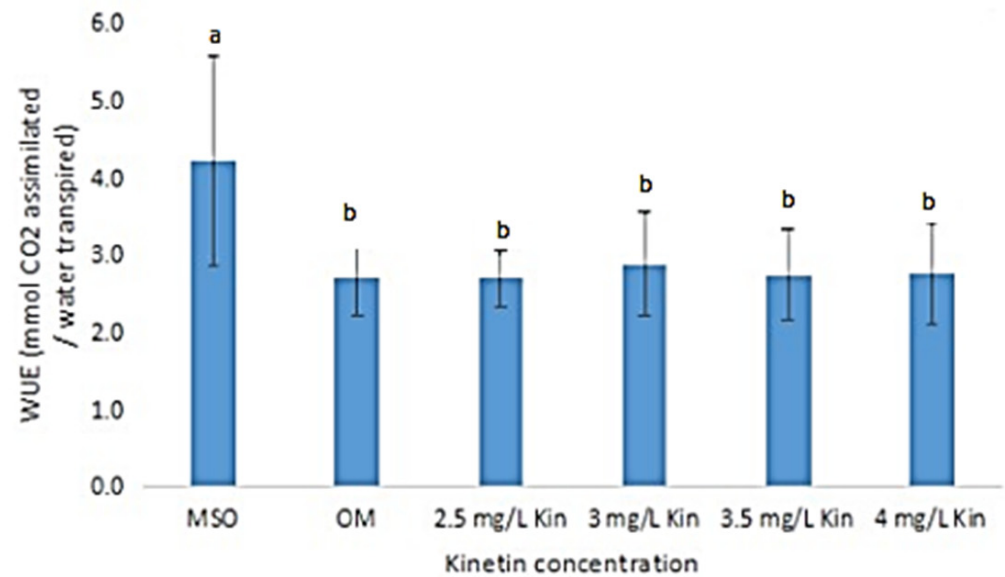

Figure 13. Water use efficiency (WUE) of plants exposed to: (a) salt stress; (b) ABA; (c) high kinetin levels. Means with different letters are significantly different at $p<0.05$ according to Duncan's multiple range test (DMRT).

\subsubsection{Maximum Efficiency and Yield of Photosystem II}

Exposure to stress was observed to lead to a reduction in the maximum efficiency of photosystem II $\left(\mathrm{F}_{\mathrm{v}} / \mathrm{F}_{\mathrm{m}}\right)$ of the plantlet samples as compared with that of plantlets grown on MSO and OM (Figure 14). As the concentration of $\mathrm{NaCl}$ increased, the $\mathrm{F}_{\mathrm{v}} / \mathrm{F}_{\mathrm{m}}$ 
also decreased with the lowest efficiency measured at $0.003 \mathrm{mg} / \mathrm{L} \mathrm{NaCl}$ (Figure 14a). However, the decrease in $\mathrm{F}_{\mathrm{v}} / \mathrm{F}_{\mathrm{m}}$ at other $\mathrm{NaCl}$ concentrations was not significant. As shown in Figure $14 \mathrm{~b}$, exposure to $2 \mu \mathrm{M}$ ABA was observed to result in the lowest $\mathrm{F}_{\mathrm{v}} / \mathrm{F}_{\mathrm{m}}$ $(0.45 \pm 0.06)$ as compared with other ABA stress levels. Increases in kinetin concentrations (up to $3.0 \mathrm{mg} / \mathrm{L}$ ) were also found to reduce $\mathrm{F}_{\mathrm{v}} / \mathrm{F}_{\mathrm{m}}$. However, a further increase in kinetin concentration was found to be insignificant in influencing the $\mathrm{F}_{\mathrm{v}} / \mathrm{F}_{\mathrm{m}}$ levels of the samples (Figure $14 \mathrm{c})$. Meanwhile, Figure 15 shows that the yield of photosystem II $\left(\mathrm{F}_{\mathrm{V}} / \mathrm{F}_{\mathrm{O}}\right)$ also decreased when the plantlets were exposed to stress.

(a)

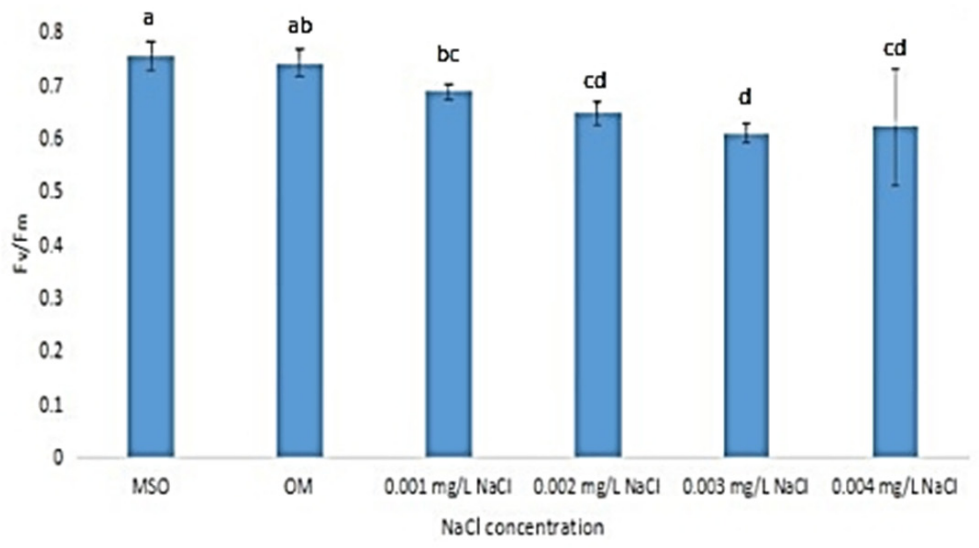

(b)

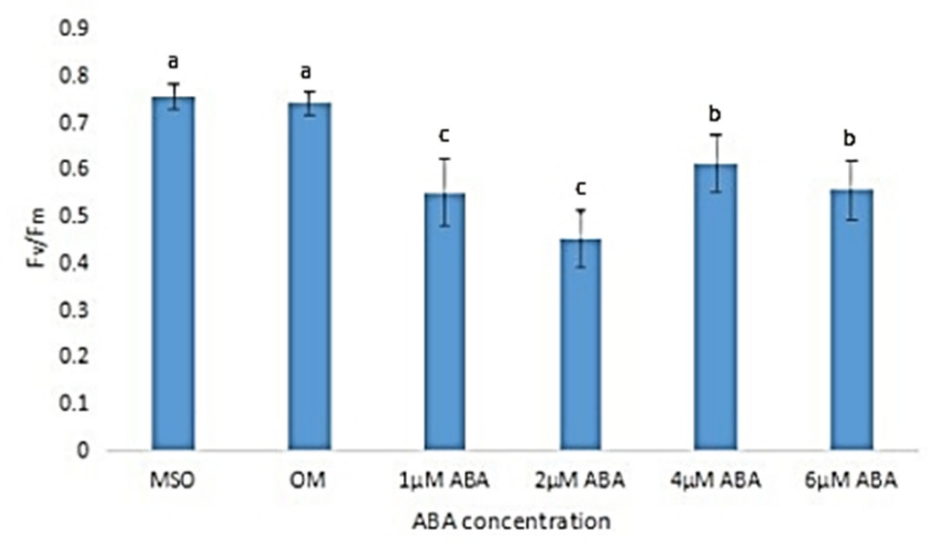

(c)

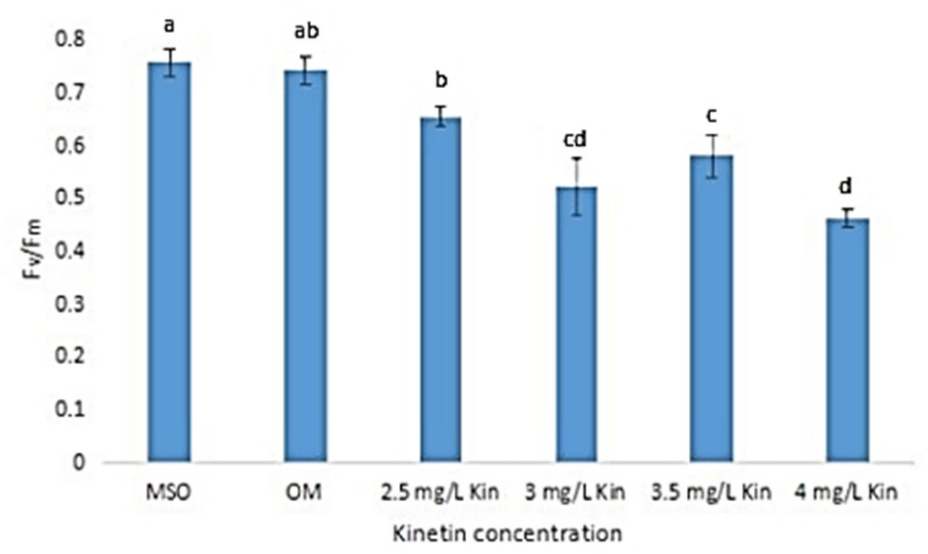

Figure 14. $\mathrm{F}_{\mathrm{v}} / \mathrm{F}_{\mathrm{m}}$ of plants exposed to: (a) salt stress; (b) ABA; (c) high kinetin levels. Means with different letters are significantly different at $p<0.05$ according to Duncan's multiple range test (DMRT). 
(a)

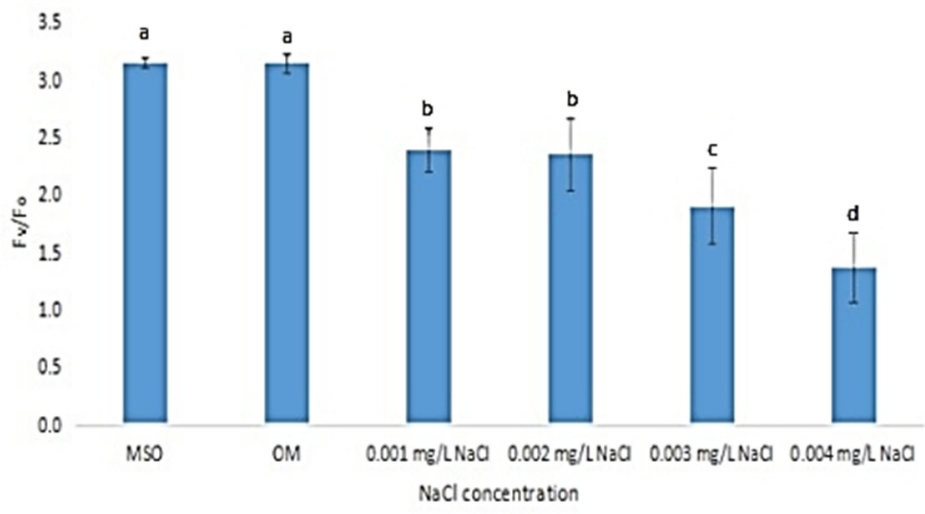

(b)

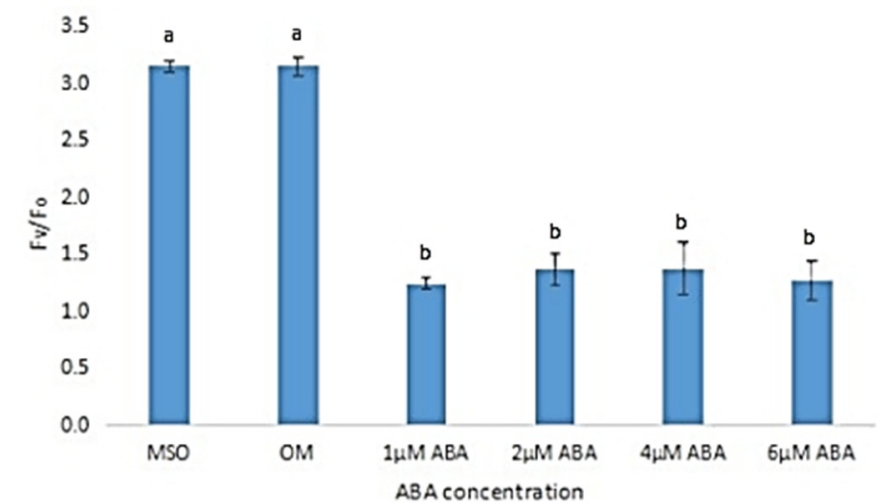

(c)

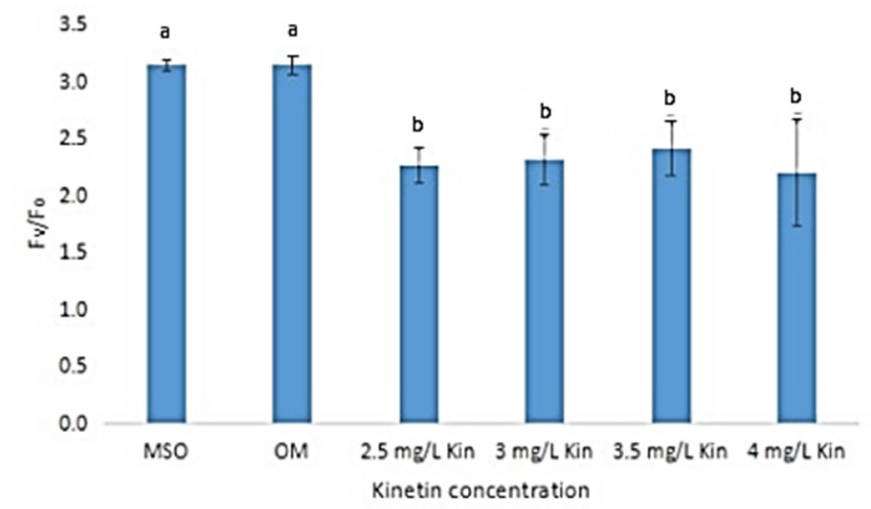

Figure 15. $\mathrm{F}_{\mathrm{V}} / \mathrm{F}_{\mathrm{O}}$ of plants exposed to: (a) salt stress; (b) ABA; (c) high kinetin levels. Means with different letters are significantly different at $p<0.05$ according to Duncan's multiple range test (DMRT).

\subsubsection{Minimal Fluorescence}

The plants grown on OM and MS0 were both found to exhibit significantly lower mean minimal fluorescence $\left(\mathrm{F}_{\mathrm{o}}\right)$ values as compared with plantlets exposed to salinity, $\mathrm{ABA}$, and high cytokinin stresses. For salinity stress (Figure 16a), the mean $\mathrm{F}_{\mathrm{o}}$ value increased with an increase in $\mathrm{NaCl}$ concentrations, however, the increase was observed to be not statistically significant. In ABA stress (Figure 16b), the mean $F_{o}$ values increased as ABA concentrations increased, however, the increase was also found to be statistically insignificant. Apart from that, as shown in Figure 16c, as kinetin concentrations increased, the mean $\mathrm{F}_{\mathrm{o}}$ values were also observed to increase, with $4.0 \mathrm{mg} / \mathrm{L}$ kinetin recorded the highest $\mathrm{F}_{\mathrm{o}}$ of $823.20 \pm 15.51$. 
(a)

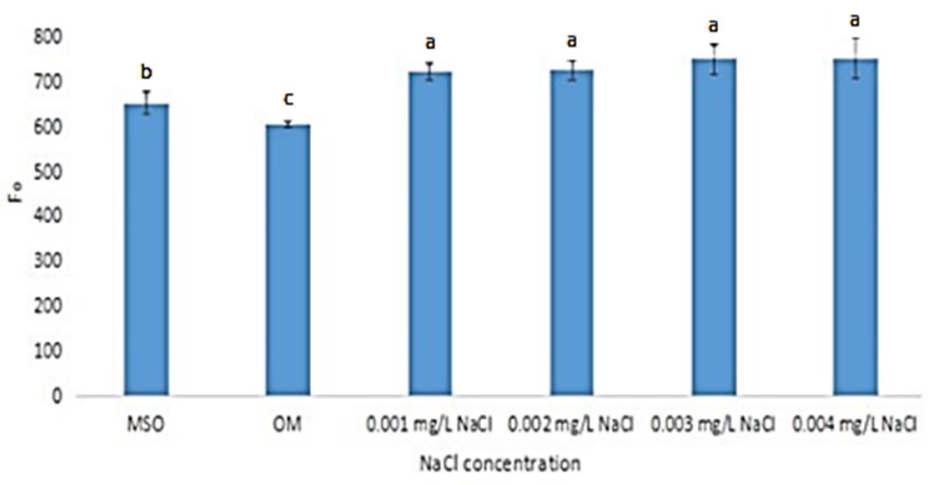

(b)

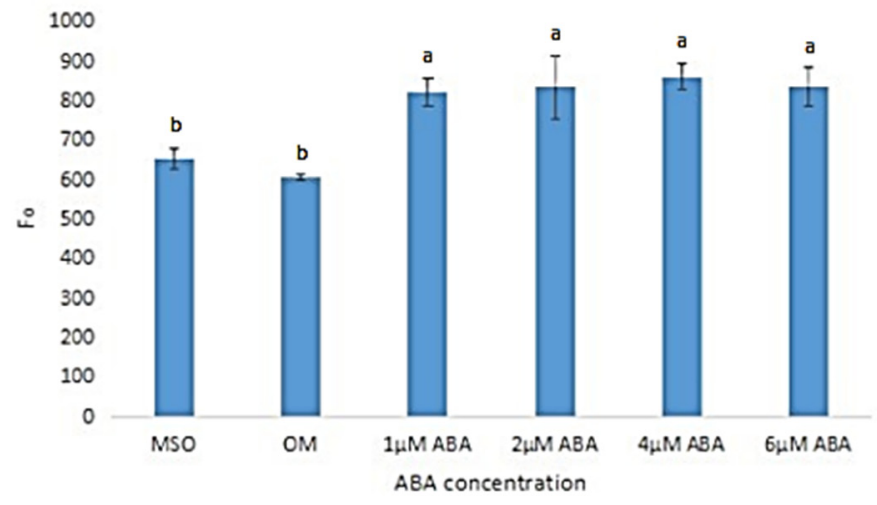

(c)

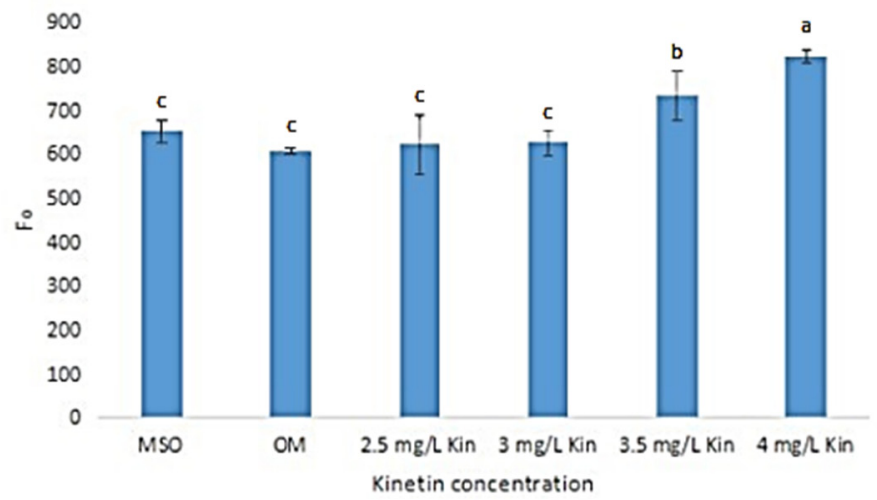

Figure 16. Minimal fluorescence $\left(\mathrm{F}_{\mathrm{o}}\right)$ of plants exposed to: (a) salt stress; $(\mathbf{b}) \mathrm{ABA}$; (c) high kinetin levels. Means with different letters are significantly different at $p<0.05$ according to Duncan's multiple range test (DMRT).

\subsubsection{Performance Index}

Performance index refers to the calculation of total photosynthetic efficiency that gives quantitative data on the condition of plant performance. It is a useful tool for assessing plants under stressful conditions. As shown in Figure 17, plantlets grown on MS0 and $\mathrm{OM}$ recorded the highest mean performance index value as compared with other plantlets exposed to abiotic stresses. As the concentration of $\mathrm{NaCl}$ increased, the performance index of plantlets subjected to salinity stress reduced insignificantly, as shown in Figure 17a. Meanwhile, the performance index of plants under ABA stress decreased drastically, from $1.76 \pm 0.23$ to $0.70 \pm 0.77$ (Figure $17 \mathrm{~b}$ ). As shown in Figure $17 \mathrm{c}$, the performance index shows a gradual decreasing trend with an increase in kinetin level. From $2.5 \mathrm{mg} / \mathrm{L}$ kinetin to $4.0 \mathrm{mg} / \mathrm{L}$ kinetin, the mean value of performance index decreased from $1.81 \pm 0.09$ to $1.39 \pm 0.07$. 
(a)

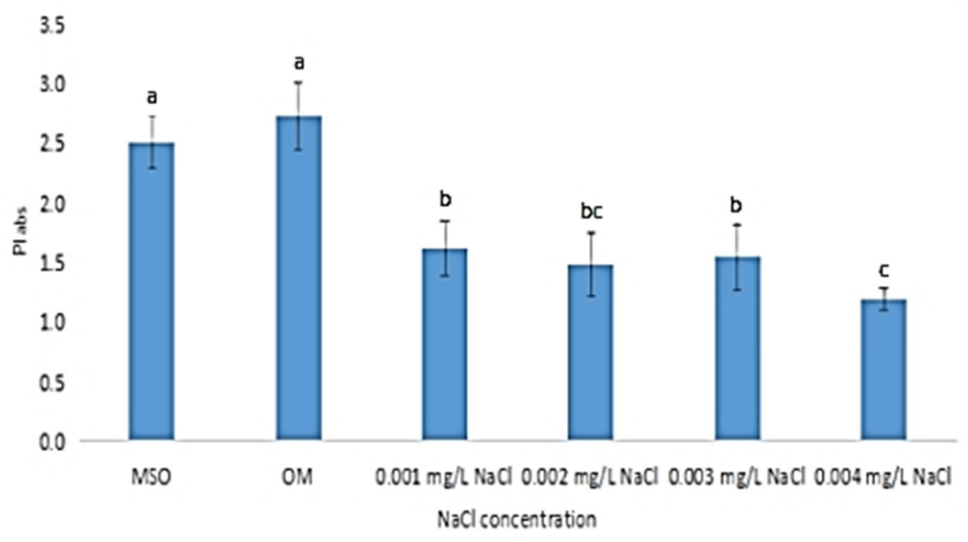

(b)

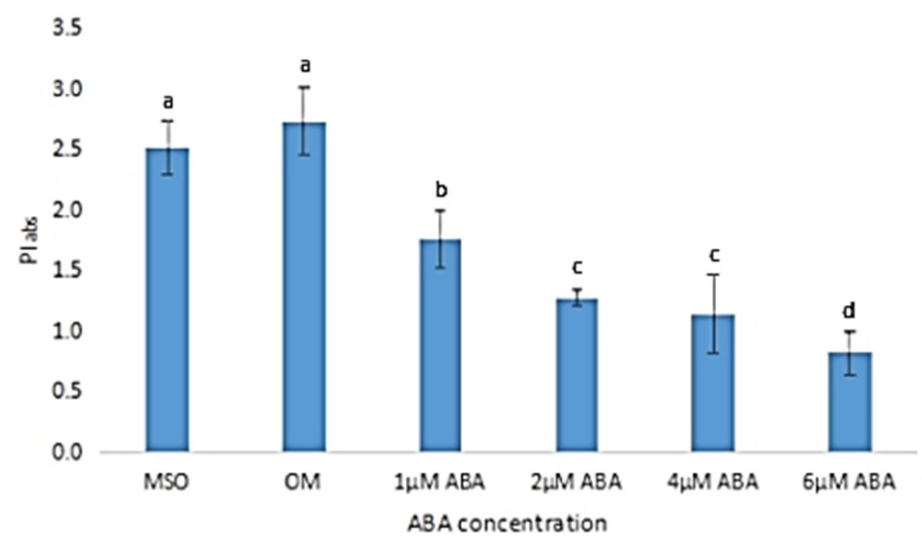

(c)

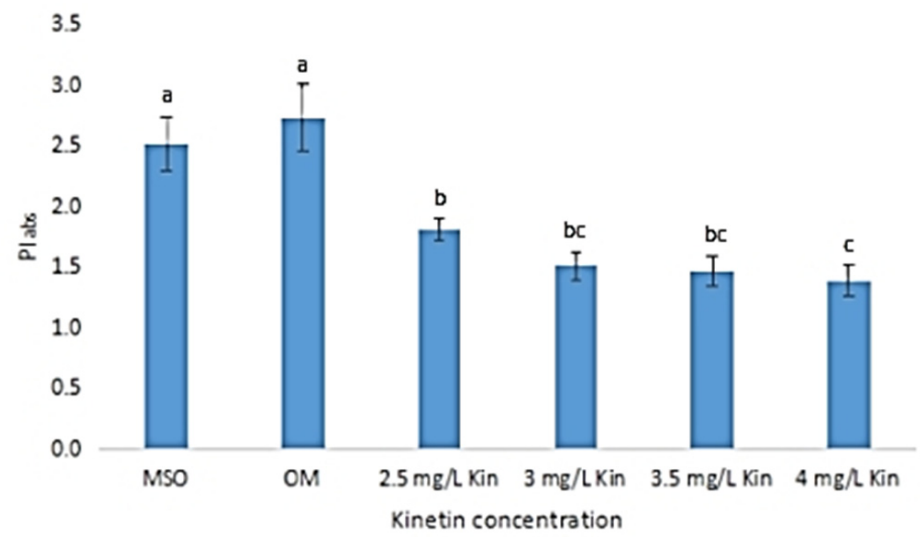

Figure 17. Performance index (PI) of plants exposed to: (a) salt stress; (b) ABA; (c) high kinetin levels. Means with different letters are significantly different at $p<0.05$ according to Duncan's multiple range test (DMRT).

\subsubsection{RC/ABS Value}

The RC/ABS value corresponds to the density of RCs on a chlorophyll, which is determined as the ratio of the reaction center chlorophyll to the antenna chlorophyll. MS0 and OM showed the highest RC/ABS values (Figure 18). The RS/ABS values for plantlets subjected to salinity stress decreased as the salt concentration rose (Figure 18a). At $0.3 \%$ $\mathrm{NaCl}$, the $\mathrm{RC} / \mathrm{ABS}$ value was the lowest $(0.3660 \pm 0.17)$. Figure $18 \mathrm{~b}$ shows that an increase in ABA concentration resulted in a decrease in RC/ABS values as compared with that exhibited by plantlets grown on MS0 and OM, however, the decrease did not follow a pattern. Apart from that, as shown in Figure 18c, the RC/ABS value was observed to drop drastically to $0.3280 \pm 0.07$ at $4.0 \mathrm{mg} / \mathrm{L}$ kinetin. 
(a)

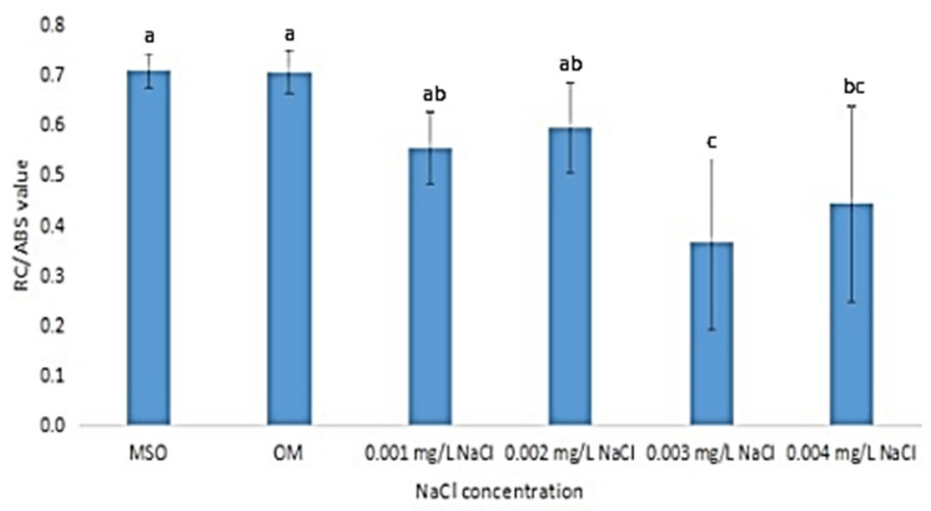

(b)

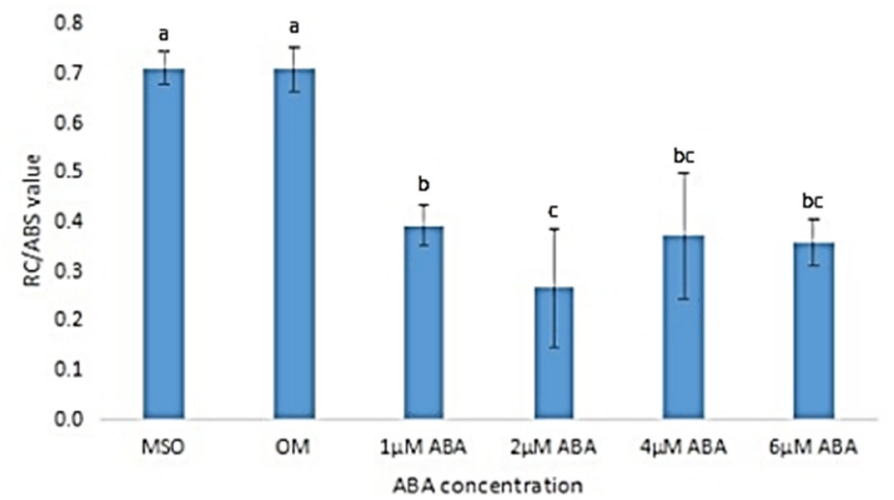

(c)

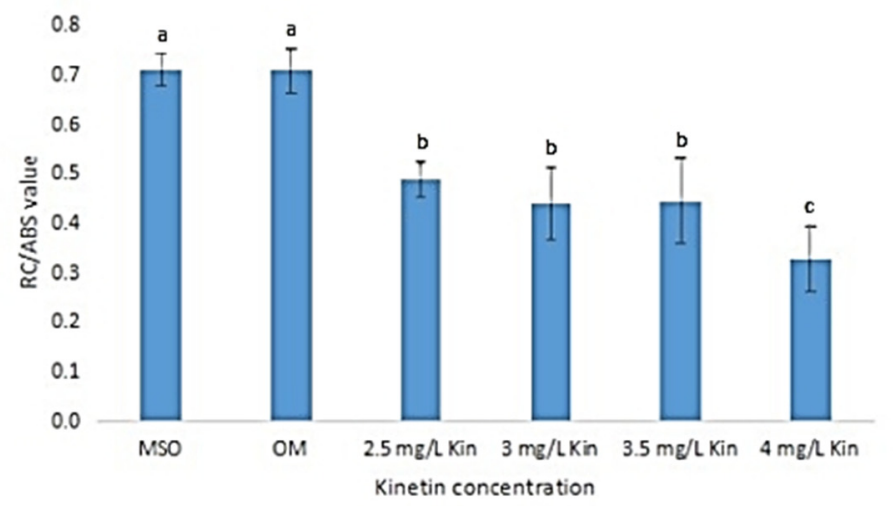

Figure 18. RC/ABS values of plants exposed to: (a) salt stress; (b) ABA; (c) high kinetin levels. Means with different letters are significantly different at $p<0.05$ according to Duncan's multiple range test (DMRT).

\subsubsection{Pearson's Correlation Analysis}

Based on Table 9, the Pearson's correlation analysis among other parameters showed that the net photosynthesis had a significant and strong positive relationship with maximum efficiency of photosystem II $\left(\mathrm{F}_{\mathrm{v}} / \mathrm{F}_{\mathrm{m}}\right)$, maximum yield of photosystem II $\left(\mathrm{F}_{\mathrm{v}} / \mathrm{F}_{\mathrm{o}}\right)$, and performance index (PI) have a significant and strong positive relationship. In contrast, the opposite trend was observed between the MDA levels and photosystem II $\left(\mathrm{F}_{\mathrm{v}} / \mathrm{F}_{\mathrm{m}}\right)$, maximum yield of photosystem II $\left(\mathrm{F}_{\mathrm{V}} / \mathrm{F}_{\mathrm{O}}\right)$, performance index $(\mathrm{PI})$, and net photosynthesis. These indicate that exposure to stress (reflected by high MDA levels) would result in a decrease in net photosynthesis of the plantlets, which would then, contribute to reductions in photosystem II efficiency $\left(\mathrm{F}_{\mathrm{v}} / \mathrm{F}_{\mathrm{m}}\right)$, maximum yield of photosystem II $\left(\mathrm{F}_{\mathrm{V}} / \mathrm{F}_{\mathrm{O}}\right)$, and performance index $(\mathrm{PI})$. 
Table 9. Pearson's correlation coefficients between physiological parameters.

\begin{tabular}{|c|c|c|c|c|c|c|c|c|c|c|c|}
\hline & SPAD & MDA & $\begin{array}{c}\text { Net of } \\
\text { Photosynthesis }\end{array}$ & Transpiration & $\begin{array}{c}\text { Stomatal } \\
\text { Conductance }\end{array}$ & WUE & $\mathrm{F}_{\mathrm{v}} / \mathrm{F}_{\mathrm{m}}$ & $F_{v} / F_{0}$ & $F_{\mathbf{o}}$ & PI & RC/ABS \\
\hline SPAD & 1 & & & & & & & & & & \\
\hline MDA & $-0.632 * *$ & 1 & & & & & & & & & \\
\hline Net of photosynthesis & $0.731^{* *}$ & $-0.607 * *$ & 1 & & & & & & & & \\
\hline Transpiration & $0.712 * *$ & $-0.556^{* *}$ & $0.782^{* *}$ & 1 & & & & & & & \\
\hline Stomatal conductance & $0.742^{* *}$ & $-0.592^{* *}$ & $0.529 * *$ & $0.548^{* *}$ & 1 & & & & & & \\
\hline WUE & -0.017 & -0.163 & 0.112 & $-0.352 * *$ & $-0.063^{* *}$ & 1 & & & & & \\
\hline $\mathrm{Fv} / \mathrm{fm}$ & 0.613 & $-0.645^{* *}$ & $0.478^{* *}$ & $0.416^{* *}$ & $0.607^{* *}$ & 0.080 & 1 & & & & \\
\hline Fo & $-0.630 * *$ & $0.638^{* *}$ & $-0.733^{* *}$ & $-0.632 * *$ & $-0.505^{* *}$ & -0.102 & $-0.477^{* *}$ & $-0.682 * *$ & 1 & & \\
\hline PI & $0.743 * *$ & $-0.699 * *$ & $0.814^{* *}$ & $0.659 * *$ & $0.686^{* *}$ & 0.108 & $0.559 * *$ & $0.725^{* *}$ & $-0.614^{* *}$ & 1 & \\
\hline $\mathrm{RC} / \mathrm{ABS}$ & $0.666^{* *}$ & $-0.647^{* *}$ & $0.650^{* *}$ & $0.583^{* *}$ & $0.555^{* *}$ & 0.077 & $0.705^{* *}$ & $0.663^{* *}$ & $-0.562^{* *}$ & $0.634^{* *}$ & 1 \\
\hline
\end{tabular}

** Correlation is significant at the 0.01 level (1-tailed) 


\section{Discussion}

One of the primary goals of mass plant propagation via tissue culture is to produce high-quality clonal plantlets. It is an important task to secure genetic uniformity of in vitro grown plantlets for mass production of important crops or cultivars such as rice [13], cotton [14], and sugarcane [15], as well as for conservation of endangered plant species [16,17]. Plant tissue culture also enables the consistent cultivation of clonal plants, which may also be utilized as plant factories to produce novel and significant bioactive chemicals with medicinal properties $[18,19]$.

Many marker systems have been used in the assessments of genetic variations among clonal plants, such as random amplified polymorphic DNA (RAPD), inter-simple sequence repeat (ISSR), simple sequence repeat (SSR), and amplified fragment length polymorphism (AFLP). ISSR has been reported to be a more effective molecular marker than RAPD and SSR. Various reports have indicated that ISSR can reveal higher polymorphism than RAPD, such as in studies on Tilletia indica [20]. The usage of ISSR markers reveals a larger number of polymorphic fragments per primer than RAPD because of the occurrence of abundant SSR regions [21].

Due to this, ISSR has been suggested as an alternative to replace RAPD in genetic diversity assessment of coconut germplasm [22]. Moreover, ISSR is also able to detect a higher similarity index than RAPD $[20,21,23,24]$, possibly due to the abundant and highly polymorphic nature of the ISSR microsatellites caused by the slippage in DNA replication [24]. ISSR has been widely used to help ascertain clonal fidelity and to reveal any occurrence of somaclonal variation among tissue culture plants, such as Magnolia sirindhorniae Noot. \& Chalermglin [25], Abutilon indicum [26], Fritillaria dagana [27], Eleusine coracana (L.) Gaertn. [28], Smallanthus sonchifolius (Poepp. and Endl.) H. Robinson [29], Morus sp. [30], and bamboos [31].

The use of ISSR markers in this species indicated $7.32 \%$ polymorphism and low genetic variation among the samples selected at random [9]. The clonal character of the in vitro O. stamineus regenerants generated in previous work was confirmed by the low genetic distance among the examined samples [9]. Nevertheless, exposing the plantlets to abiotic stresses can cause plants to exhibit somaclonal variation, which cause the plantlets to have a unique characteristic that is different than the mother plant. The results obtained in this study showed a high genetic variation in all somaclonal variants as compared with the mother plant and plants grown on MS0 and OM. The use of ISSR markers in this study indicated $70.12 \%$ polymorphism and a high genetic distance among the stressed plantlets. This was likely to occur due to somaclonal variation induced by the abiotic stresses used in this study. The high polymorphism percentage is evidence of wide genetic variation in the variants. Plant regeneration ability was genotype dependent, and it was also significantly linked to a normal DNA content [32]. In this study, the samples were collected after the third subculture because the regenerants were considered to be genetically stable after three to four months of culture [33].

There were many types of abnormal phenotypes observed in the O. stamineus culture such as scorched leaf, variegated leaves, smooth edge leaves, leaves with undulated margin, and dwarfed plantlets. For leaf variegation, the leaves were observed to possess chlorophyll pigments in the middle, while no chlorophyll pigments could be observed around the outside. By using a starch test, only the area with the chlorophyll showed a positive result, because starch could only be made with the presence of chlorophyll. Regarding the occurrence of dwarfed plantlets, it may have arisen due to zinc deficiency that caused older leaves to remain small with a slight discoloration between the veins and caused the plant growth to be stunted. However, the more severe the stress, the slower the rate of development [34].

Exposure to high kinetin concentrations was found to induce high occurrence of hyperhydricity, which was observed to occur in up to one third of the leaves per explant. In this study, hyperhydricity was shown to be more prominent than other variants' phenotypes. Hyperhydricity can be caused by a decrease in the transpiration rate due to high water 
availability in the nutrient medium. It has also been linked to the fact that the growth container has a high relative humidity level [35]. The majority of the upward translocation in growing plants occurs in the xylem, which is driven by root pressure and leaf transpiration. However, some plantlets in tissue culture may not establish roots. Transpiration from the leaves did occur but this was unlikely to be the source of the excess water in intercellular gaps since water in the hyperhydric tissues did not evaporate efficiently. Water flow in the phloem is driven by a differential pressure between the source and sink, but in tissue culture, such water transfer from the medium to the intercellular space is not viable [36]. Meanwhile, exposure to salinity caused the osmotic pressure to rise, making it more difficult for roots to extract water, and thus, resulted in dehydration symptoms. This caused $\mathrm{Na}+$ and $\mathrm{Cl}$ - uptake to continue to rise, resulting in toxic concentrations of these ions, hence, leading to leaf damage and delayed growth [37]. A previous study indicated that increasing salinity would harm photosynthetic pigmentation, lipid peroxidation, protein content, and proline content as compared to the control group [38].

In addition, exposure to salinity stress has been found to lead to stunted growth of O. stamineus. Parallel to this observation, salinity has been reported to affect the number of leaves, plant height, root weight, total gel weight, and dry root weight of aloe vera, where the height and number of leaves of plants decreased when the concentration of $\mathrm{NaCl}$ was high [38-40]. Root development was also significantly hindered in salt-stressed O. stamineus plantlets, indicating that salinity stress had a negative impact on root formation. In a study on Stevia rebaudiana, $\mathrm{NaCl}$ treatment was found to reduce root numbers and plant weights, while boosting the antioxidant capacity, hydroxycinnamic acid, and total soluble sugar content [41]. Meanwhile, plant growth, development, and metabolism have also been affected by salt stress [41]. Moreover, the addition of $\mathrm{NaCl}$ to the growth media in centaury shoots and roots was observed to result in an increase in all biochemical parameters [42].

In this study, plantlets exposed to ABA stress produced translucent yellow-greenish leaves, indicating hyperhydricity (Figure 2). Plants appear to benefit more from ABA produced in leaves than in roots during stress control, in order to prevent excessive water potential reductions [43]. Abiotic stress is affected by ABA in stomatal guard cells [44], and it has the potential to influence plant hyperhydricity. However, the production of shoots and leaves were observed to be not significantly different throughout all ABA concentrations tested. These observations are in contrast to that observed in Swertia chirayita, which demonstrated a decline in in vitro shoot growth as ABA concentrations increased [45]. The occurrence of hyperhydricity also increased as kinetin concentration increased. The leaves of the plantlets were visibly green in color, despite becoming translucent. Higher amounts of kinetin in the samples may have damaged the chloroplasts, thus, limiting the synthesis of photosynthetic pigments, causing the leaves to become greenish [46].

Physiological, genetic, and metabolic factors all played roles in the incidence of somaclonal variance. The equilibrium of plant growth regulators and stress in the media has an effect on the variants' DNA levels. For example, when auxins (IAA, IBA, and NAA) and cytokinins (BA and TDZ) are used in micropropagated Cavendish bananas, greater multiplication rates, and therefore, more variations (up to $72 \%$ ) were generated [47]. High multiplication rates may disrupt the layered structure of the meristem or cause shoots to form adventitiously from single cells, thus, increasing the possibility of somaclonal variation [48].

In addition, morphological changes may be caused by DNA sequence alterations in the variants. As a result, aberrant DNA content has been linked to severe hyperhydricity symptoms [32]. It has been previously reported that hyperhydric shoots often showed higher MDA concentrations than non-hyperhydric shoots [49]. MDA is the product of polyunsaturated fatty acid breakdown, and has been used as a diagnostic identification for lipid peroxidation. MDA has been reported to not only increase the expression of a broad range of genes, but the gene set has been observed to be skewed toward genes implicated in abiotic stress responses [50]. 
The most common types of variations observed in plant tissue cultures include physiological and biochemical variations. Unless a particular test is conducted, many of these changes are hardly detectable. Several biochemical differences have been discovered in plant tissue culture. Some of these variations have been reported to be Mendelian in nature, however, many have also been reported to be epigenetically regulated, and thus, may be lost in the regenerated plants [51]. In addition, biochemical differences that could be produced via tissue culture include starch production, alterations of the carotenoid pathway, nitrogen metabolism, antimicrobial resistance, and others.

In this study, somaclonal variation in O. stamineus was observed to be driven by a decrease in photosynthetic capability due to variations caused by carbon metabolism. Because morphological observation alone is insufficient for a comprehensive understanding of the situation, in this study, a variety of physiological analyses were also carried out to elucidate the effects of salinity, ABA, and supplementation of high kinetin levels on in vitro $O$. stamineus plantlets. The data analysis revealed that the photosynthesis abilities of the variants may have been negatively impacted as a result of decreased chlorophyll contents caused by the stresses. The ratio of chlorophyll a to chlorophyll $b$ was found to be much lower. There was also a significant difference in chlorophyll a and chlorophyll b concentrations. Higher chlorophyll b levels, relative to chlorophyll a levels, showed that chlorophyll a was rapidly destroyed under stress, resulting in a higher concentration of the accessory pigment (chlorophyll $b$ ). In this study, the chlorophyll $b$ and the total chlorophyll $(\mathrm{a}+\mathrm{b})$ contents were observed to increase, while the chlorophyll a content was decreased. In addition, the amounts of chlorophyll $b$ were also discovered to be higher than chlorophyll a, when the O. stamineus plantlets were exposed to higher concentrations of kinetin. These observations are parallel to results reported in Zea mays, where supplementation with increasing kinetin concentration resulted in a decrease in chlorophyll pigments content [52]. It has been reported that higher levels of kinetin may destroy the chloroplast, thus, impairing the production of photosynthetic pigments due to excessive lipid peroxidation and hydrogen peroxide levels [46].

Moreover, higher salinity was observed to result in a decreased SPAD value, indicating that in situ chlorophyll content declined as stress levels increased. This was also reflected in the leaf color, as evidenced by the fact that the plants' leaves displayed abnormal pigmentation at higher salinity stress, which resulted in the leaves appearing white. The data analysis showed that the SPAD value has a significant correlation with net photosynthesis, stomatal conductance, and transpiration rate, indicating that the increase in chlorophyll contents led to a higher $\mathrm{CO}_{2}$ assimilation. Because the diffusion routes for $\mathrm{H}_{2} \mathrm{O}$ and $\mathrm{CO}_{2}$ are similar, the stomatal conductance and transpiration rates are usually linked. Kinetin has also been attributed to decreased water permeability in roots, which has an impact on plants' physiological activities such as net photosynthesis [53]. These could explain the incidence of lower SPAD readings in O. stamineus plants when they were exposed to high concentrations of kinetin, which, in turn, affected the net photosynthesis and transpiration rates of the plants.

The minimal fluorescence showed a significant negative relationship with net photosynthesis and transpiration rate. The plant's ability to absorb $\mathrm{CO}_{2}$ was thus, decreased when stress levels increased, which would eventually lead to a disruption in the plant's growth and photosynthetic capability [54]. The leaves of the plantlets were also observed to exhibit an abnormal pigmentation, indicating that they had gone through somaclonal variation [55]. The rate at which $\mathrm{CO}_{2}$ or $\mathrm{H}_{2} \mathrm{O}$ travels through the stomata of a leaf is measured by stomatal conductance. Stomata have two important roles in plants, whereby, they control $\mathrm{CO}_{2}$ entry into the leaf and also control transpiration, which supplies nutrients to the plant. Long-term salt exposure has been reported to induce ionic stress in plants, which leads to leaf senescence and photosynthetic impairment, as well as dehydration. For example, stomata progressively close under drought conditions, resulting in a reduction in WUE (water use efficiency) and net photosynthetic activity. These is also accompanied by changes in photosynthetic pigments, as well as other factors [56]. 
Plant pigments are vital in photosynthetic processes, as well as in determining the physiological status of a plant, thus, serving as an efficient stress indicator [57]. In photosynthesis, various mechanisms such as the electron transport chain, gas exchange systems, photosynthetic pigments, and photosystems are involved, thus, any deficiency in one of these parameters can decrease the plant's photosynthetic performance [58]. In this study, the Pearson's correlation analysis results revealed that there were significant positive correlations between net photosynthesis and the following: photosystem II maximum efficiency $\left(\mathrm{F}_{\mathrm{v}} / \mathrm{F}_{\mathrm{m}}\right)$, maximum yield $\left(\mathrm{F}_{\mathrm{v}} / \mathrm{F}_{\mathrm{o}}\right)$, performance index $(\mathrm{PI})$, and density of reaction centers per photosystem II antenna chlorophyll (RC/ABS). Net photosynthesis is defined as the difference between the total amount of photosynthesis and the sum of the rates of respiration, which means that a higher value of net photosynthesis indicates higher photosynthetic activity. According to the data, when salt and ABA stress levels were increased, net photosynthesis, $\mathrm{F}_{\mathrm{v}} / \mathrm{F}_{\mathrm{m}}, \mathrm{F}_{\mathrm{v}} / \mathrm{F}_{\mathrm{o}}$, and PI of the plantlets were all decreased. This was because stressed plants were unable to perform photosynthesis efficiently due to the changes in their physiology.

Furthermore, minimal chlorophyll fluorescence $\left(\mathrm{F}_{\mathrm{o}}\right)$ and malondialdehyde (MDA) concentration were the only two physiological measures that exhibited a rising trend with increasing salinity and ABA stress. Data analysis also revealed that the MDA content was increased as the concentrations of kinetin in the regeneration medium increased. It has been reported that an increase in MDA levels indicated an increase in lipid peroxidation [59], thus, suggesting that the $O$. stamineus plant's defensive mechanism had been activated in response to stress. In addition, lipid peroxidation has been reported to serve as a biomarker for oxidative stress, thus, higher MDA levels accompanied by high lipid peroxidation activities indicated that the plants are under a high level of stress [60].

The increase in $\mathrm{F}_{\mathrm{o}}$ and reduction in $\mathrm{F}_{\mathrm{v}} / \mathrm{F}_{\mathrm{m}}$ that were observed in this study have been linked to the physical separation of PSII reaction centers from their associated pigment antenna (chlorophyll b), thus, resulting in limited energy transmission of the PSII traps. PSII activity has also been reported to be reduced as a result of other factors such as leaf senescence, as assessed by chlorophyll fluorescence analysis [61]. When exposed to various kinetin levels, the $O$. stamineus plants's PI was observed to decrease, which could be due to a decrease in any of the following three independent parameters: the density of fully active RCs, electron transport efficiency, or the probability that an absorbed photon would be trapped by the photosynthesis reaction centers [62].

In a condition with limited $\mathrm{CO}_{2}$ supply, such as due to the closure of stomata, plant leaves show greater energy dissipation and partial deactivation of PSII reaction centers, hence, decreasing the energy input to the electron transport chain in order to prevent overexcitation and photodamage [63]. PI measures the functioning of both photosystems I and II and provides quantitative data about the status of plant performance under stress [64]. In this study, salinity stress was observed to lower the plants' PI, whereby, these observations were connected to a reduction in the active reaction centers, electron trapping, and electron transfer to the electron transport chain during photosynthesis [65]. In addition, an increase in salinity also causes the functional antenna size to grow, hence, putting the photosynthetic system under continual excitation pressure, and resulting in energy loss and decreased oxygen production [66]. However, contrary to the findings in this study, the photon absorption (RC/ABS) in the Phalaenopsis orchids was observed to increase significantly after 4 weeks of drought stress, although no significant changes were observed in the plant's chlorophyll a, chlorophyll b, or total chlorophyll [63].

\section{Conclusions}

Exposure to several abiotic stress factors such as high salinity, ABA, and high kinetin levels was found to result in the occurrence of somaclonal variation in Orthosiphon stamineus, a valuable medicinal plant. The somaclonal variants were observed to display various morphological irregularities, however, the incidence of hyperhydricity (vitrification) was identified as the most prominent. An ISSR-based analysis revealed that there was a large 
genetic distance between the somaclonal variants and the mother plant. The results of this study also indicated that an increase in abiotic stress levels (reflected by the high MDA levels) caused a reduction in the photosynthetic ability of the plantlets. Chlorophyll concentrations also decreased with increasing stress levels, implying that altering the plantlets' reactions to stress may be used as a way to boost the synthesis of certain metabolites. Nevertheless, more studies on the metabolites that are produced as a result of stress exposure should be conducted to elucidate the metabolic pathways that are linked to somaclonal variation.

Author Contributions: J.S.Y. and N.A.M.Z. conceived and designed the research; H.A., N.S. and N.H.A.S. conducted the experiments; J.S.Y., N.A.M.Z. and M.H.I. contributed reagents and analytical tools; H.A., N.S. and N.H.A.S. analyzed data; H.A. and J.S.Y. wrote the manuscript. All authors have read and agreed to the published version of the manuscript.

Funding: This research was funded by the Universiti Malaya, Malaysia, grant numbers RU004C-2020 and PG156-2014B.

Institutional Review Board Statement: Not applicable.

Informed Consent Statement: Not applicable.

Data Availability Statement: Not applicable.

Acknowledgments: The authors thank the Universiti Malaya, Malaysia for experimental facilities and financial support (grant numbers RU004C-2020 and PG156-2014B) to carry out the work.

Conflicts of Interest: The authors declare no conflict of interest. The funders had no role in the design of the study; in the collection, analyses, or interpretation of data; in the writing of the manuscript; or in the decision to publish the results.

\section{References}

1. Chan, K. Some Aspects of Toxic Contaminants in Herbal Medicines. Chemosphere 2003, 52, 1361-1371. [CrossRef]

2. Basheer, M.K.A.; Majid, A.M.S.A. Medicinal Potentials of Orthosiphon Stamineus Benth. WebmedCentral Cancer 2010, 1, WMC001361.

3. Koay, Y.C.; Amir, F. A Survey of the Chemical Constituents and Biological Activities of Orthosiphon Stamineus. Sci. Int. 2012, 24, 133-138.

4. Nawi, I.M.; Abd Samad, A. Successful Plant Regeneration of Orthosiphon Stamineus from Petiole. J. Med. Plants Res. 2012, 6, 4276-4280.

5. Liang, L.F.; Keng, C.L.; Lim, B.P. Selection of Cell Lines for the Production of Rosmarinic Acid from Cell Suspension Cultures of Orthosihon Stamineus Benth. Vitr. Cell. Dev. Biol.-Plant 2006, 42, 538-542. [CrossRef]

6. Dhoran, V.S.; Gudadhe, S.P. Effect of Plant Growth Regulators on Seed Germination and Seedling Vigour in Asparagus Sprengeri Regelin. Int. Res. J. Biol. Sci. 2012, 1, 6-10.

7. Hazarika, B. Morpho-Physiological Disorders in in Vitro Culture of Plants. Sci. Hortic. 2006, 108, 105-120. [CrossRef]

8. Kaeppler, S.; Phillips, R. DNA Methylation and Tissue Culture-Induced Variation in Plants. Vitr. Cell. Dev. Biol.-Plant 1993, 29, 125-130. [CrossRef]

9. Ali, H.; Musa, I.F.; Abu Bakar, N.A.; Karsani, S.A.; Yaacob, J.S. In Vitro Regeneration and ISSR-Based Genetic Fidelity Analysis of Orthosiphon Stamineus Benth. Agronomy 2019, 9, 778. [CrossRef]

10. Murashige, T.; Skoog, F. A Revised Medium for Rapid Growth and Bio Assays with Tobacco Tissue Cultures. Physiol. Plant. 1962, 15, 473-497. [CrossRef]

11. Vujović, T.; Ružić, D.; Cerović, R. In Vitro Shoot Multiplication as Influenced by Repeated Subculturing of Shoots of Contemporary Fruit Rootstocks. Hortic. Sci. 2012, 39, 101-107. [CrossRef]

12. Lichtenthaler, H.K.; Buschmann, C. Chlorophylls and Carotenoids: Measurement and Characterization by UV-VIS Spectroscopy. Curr. Protoc. Food Anal. Chem. 2001, 1, F4. 3.1-F4. 3.8. [CrossRef]

13. Hoque, M.; Ali, M.; Karim, N. Embryogenic Callus Induction and Regeneration of Elite Bangladeshi Indica Rice Cultivars. Plant Tissue Cult. Biotechnol. 2007, 17, 65-70. [CrossRef]

14. Mishra, R.; Wang, H.-Y.; Yadav, N.R.; Wilkins, T.A. Development of a Highly Regenerable Elite Acala Cotton (Gossypium hirsutum cv. Maxxa)-A Step towards Genotype-Independent Regeneration. Plant Cell Tissue Organ. Cult. 2003, 73, 21-35. [CrossRef]

15. Rashid, H.; Khan, S.A.; Zia, M.; Chaudhary, M.F.; Hanif, Z.; Chaudary, Z. Callus Induction and Regeneration in Elite Sugarcane Cultivar HSF-240. Pak. J. Bot 2009, 41, 1645-1649.

16. Dang, J.C.; Kumaria, S.; Kumar, S.; Tandon, P. Micropropagation of Ilex Khasiana, a Critically Endangered and Endemic Holly of Northeast India. AoB Plants 2011, 2011, plr012. [CrossRef] [PubMed] 
17. Markovic, M.; Grbic, M.; Djukic, M. Micropropagation of Endangered and Decorative Species Dianthus Pinifolius Sibth. et Sm. Braz. Arch. Biol. Technol. 2016, 59, 1-8. [CrossRef]

18. Dias, M.I.; Sousa, M.J.; Alves, R.C.; Ferreira, I.C. Exploring Plant Tissue Culture to Improve the Production of Phenolic Compounds: A Review. Ind. Crops Prod. 2016, 82, 9-22. [CrossRef]

19. Ramirez-Estrada, K.; Vidal-Limon, H.; Hidalgo, D.; Moyano, E.; Golenioswki, M.; Cusidó, R.M.; Palazon, J. Elicitation, an Effective Strategy for the Biotechnological Production of Bioactive High-Added Value Compounds in Plant Cell Factories. Molecules 2016, 21, 182. [CrossRef]

20. Parveen, S.; Saharan, M.; Verma, A.; Sharma, I. Comparative Analysis of RAPD and ISSR Marker Assays for Detecting Genetic Polymorphism in Tilletia Indica. Europ. J. Exp. Biol. 2013, 3, 380-387.

21. Pathak, H.; Dhawan, V. ISSR Assay for Ascertaining Genetic Fidelity of Micropropagated Plants of Apple Rootstock Merton 793. Vitr. Cell. Dev. Biol. Plant 2012, 48, 137-143. [CrossRef]

22. Manimekalai, R.; Nagarajan, P.; Kumaran, P. Comparison of Effectiveness of RAPD, ISSR and SSR Markers for Analysis of Coconut (Cocos nucifera L.) Germplasm Accessions. Trop. Agric. Res. 2006, 18, 1-6.

23. Fernandez, M.; Figueiras, A.; Benito, C. The Use of ISSR and RAPD Markers for Detecting DNA Polymorphism, Genotype Identification and Genetic Diversity among Barley Cultivars with Known Origin. Theor. Appl. Genet. 2002, 104, 845-851. [CrossRef] [PubMed]

24. Muthusamy, S.; Kanagarajan, S.; Ponnusamy, S. Efficiency of RAPD and ISSR Markers System in Accessing Genetic Variation of Rice Bean (Vigna Umbellata) Landraces. Electron. J. Biotechnol. 2008, 11, 32-41. [CrossRef]

25. Cui, Y.; Deng, Y.; Zheng, K.; Hu, X.; Zhu, M.; Deng, X.; Xi, R. An Efficient Micropropagation Protocol for an Endangered Ornamental Tree Species (Magnolia Sirindhorniae Noot. \& Chalermglin) and Assessment of Genetic Uniformity through DNA Markers. Sci. Rep. 2019, 9, 1-10.

26. Seth, S.; Panigrahi, J. In Vitro Organogenesis of Abutilon Indicum (L.) Sweet from Leaf Derived Callus and Assessment of Genetic Fidelity Using ISSR Markers. J. Hortic. Sci. Biotechnol. 2019, 94, 70-79. [CrossRef]

27. Muraseva, D.S.; Kobozeva, E.V.; Novikova, T.I. Assessment of Genetic Fidelity of Fritillaria Dagana (Liliaceae) Regenerated Plants Using ISSR Markers. Proc. BIO Web Conf. 2018, 11, 00029. [CrossRef]

28. Babu, G.A.; Vinoth, A.; Ravindhran, R. Direct Shoot Regeneration and Genetic Fidelity Analysis in Finger Millet Using ISSR Markers. Plant Cell Tissue Organ. Cult. (PCTOC) 2018, 132, 157-164. [CrossRef]

29. Viehmannova, I.; Bortlova, Z.; Vitamvas, J.; Cepkova, P.H.; Eliasova, K.; Svobodova, E.; Travnickova, M. Assessment of Somaclonal Variation in Somatic Embryo-Derived Plants of Yacon [Smallanthus Sonchifolius (Poepp. and Endl.) H. Robinson] Using Inter Simple Sequence Repeat Analysis and Flow Cytometry. Electron. J. Biotechnol. 2014, 17, 102-106. [CrossRef]

30. Rohela, G.K.; Jogam, P.; Shabnam, A.A.; Shukla, P.; Abbagani, S.; Ghosh, M.K. In Vitro Regeneration and Assessment of Genetic Fidelity of Acclimated Plantlets by Using ISSR Markers in PPR-1 (Morus sp.): An Economically Important Plant. Sci. Hortic. 2018, 241, 313-321. [CrossRef]

31. Mudoi, K.D.; Saikia, S.P.; Goswami, A.; Gogoi, A.; Bora, D.; Borthakur, M. Micropropagation of Important Bamboos: A Review. Afr. J. Biotechnol. 2013, 12, 2770-2785.

32. Ochatt, S.J.; Muneaux, E.; Machado, C.; Jacas, L.; Pontécaille, C. The Hyperhydricity Ofin Vitroregenerants of Grass Pea (Lathyrus sativus L.) Is Linked with an Abnormal DNA Content. J. Plant Physiol. 2002, 159, 1021-1028. [CrossRef]

33. Lee, M.; Phillips, R. Genomic Rearrangements in Maize Induced by Tissue Culture. Genome 1987, 29, 122-128. [CrossRef]

34. Asghari, R.; Ahmadvand, R. Salinity Stress and its Impact on Morpho-Physiological Characteristics of Aloe Vera. Pertanika J. Trop. Agric. Sci. 2018, 41, 411-421.

35. van den Dries, N.; Giannì, S.; Czerednik, A.; Krens, F.A.; de Klerk, G.-J.M. Flooding of the Apoplast Is a Key Factor in the Development of Hyperhydricity. J. Exp. Bot. 2013, 64, 5221-5230. [CrossRef]

36. Rojas-Martínez, L.; Visser, R.G.; De Klerk, G.-J. The Hyperhydricity Syndrome: Waterlogging of Plant Tissues as a Major Cause. Propag. Ornam. Plants 2010, 10, 169-175.

37. Munns, R.; Tester, M. Mechanisms of Salinity Tolerance. Annu Rev. Plant Biol. 2008, 59, 651-681. [CrossRef] [PubMed]

38. Dogan, M. Effect of Salt Stress on in Vitro Organogenesis from Nodal Explant of Limnophila Aromatica (Lamk.) Merr. and Bacopa Monnieri (L.) Wettst. and their Physio-Morphological and Biochemical Responses. Physiol. Mol. Biol. Plants 2020, 26 , 803-816. [CrossRef]

39. Moghbeli, I.; Fathollahi, S.; Salari, H.; Ahmadi, G.; Saliqehdar, F.; Safari, A.; Sadat-Hosseini, M. Effects of Salinity Stress on Growth and Yield of Aloe vera L. J. Med. Plant. Res. 2012, 6, 3272-3277.

40. Pérez-Jiménez, M.; Pérez-Tornero, O. In Vitro Plant Evaluation Trial: Reliability Test of Salinity Assays in Citrus Plants. Plants 2020, 9, 1352. [CrossRef] [PubMed]

41. Lucho, S.R.; do Amaral, M.N.; Auler, P.A.; Bianchi, V.J.; Ferrer, M.Á.; Calderón, A.A.; Braga, E.J.B. Salt Stress-Induced Changes in In Vitro Cultured Stevia Rebaudiana Bertoni: Effect on Metabolite Contents, Antioxidant Capacity and Expression of Steviol Glycosides-Related Biosynthetic Genes. J. Plant. Growth Regul. 2019, 38, 1341-1353. [CrossRef]

42. Trifunović-Momčilov, M.; Paunović, D.; Milošević, S.; Marković, M.; Jevremović, S.; Dragićević, I.Č.; Subotić, A. Salinity Stress Response of Non-Transformed and AtCKX Transgenic Centaury (Centaurium Erythraea Rafn.) Shoots and Roots Grown in Vitro. Ann. Appl. Biol. 2020, 177, 74-89. [CrossRef] 
43. Cardoso, A.; Gori, A.; Da-Silva, C.; Brunetti, C. Abscisic Acid Biosynthesis and Signaling in Plants: Key Targets to Improve Water Use Efficiency and Drought Tolerance. Appl. Sci. 2020, 10, 6322. [CrossRef]

44. Nambara, E.; Kuchitsu, K. Opening a New Era of ABA Research. J. Plant Res. 2011, 124, 431-435. [CrossRef]

45. Shailja, S.; Kanwar, K.; Soni, M.; Singh, A. In Vitro Propagation and Conservation of an Endangered High Value Medicinal Herb Swertia Chirayita of Temperate Himalayas. Indian J. Plant Physiol. 2017, 22, 247-257. [CrossRef]

46. Wang, H.; Dai, B.; Shu, X.; Wang, H.; Ning, P. Effect of Kinetin on Physiological and Biochemical Properties of Maize Seedlings under Arsenic Stress. Adv. Mater. Sci. Eng. 2015, 2015, 714646. [CrossRef]

47. Bairu, M.W.; Fennell, C.W.; van Staden, J. The Effect of Plant Growth Regulators on Somaclonal Variation in Cavendish Banana (Musa AAA cv.'Zelig'). Sci. Hortic. 2006, 108, 347-351. [CrossRef]

48. Trigiano, R.N.; Gray, D.J. Plant Tissue Culture, Development, and Biotechnology; CRC Press: Boca Raton, FL, USA, 2016.

49. Sivanesan, I.; Song, J.; Hwang, S.; Jeong, B. Micropropagation of Cotoneaster Wilsonii Nakai-A Rare Endemic Ornamental Plant. Plant Cell Tissue Organ Cult. 2010, 105, 55-63. [CrossRef]

50. Weber, H.; Chételat, A.; Reymond, P.; Farmer, E.E. Selective and Powerful Stress Gene Expression in Arabidopsis in Response to Malondialdehyde. Plant J. 2004, 37, 877-888. [CrossRef]

51. Trigiano, R.N.; Gray, D.J. Plant Development and Biotechnology; CRC Press: Boca Raton, FL, USA, 2004.

52. Pazurkiewicz-Kocot, K.; Kita, A.; Haduch, A. The Effect of Kinetin on the Chlorophyll Pigments Content in Leaves of Zea mays L. Seedlings and Accumulation of Some Metal Ions. Inżynieria Ochr. Sr. 2011, 14, 397-409.

53. Gadallah, M.A.A. Effects of Kinetin on Growth, Grain Yield and Some Mineral Elements in Wheat Plants Growing under Excess Salinity and Oxygen Deficiency. Plant Growth Regul. 1999, 27, 63-74. [CrossRef]

54. Chaves, M.M.; Flexas, J.; Pinheiro, C. Photosynthesis under Drought and Salt Stress: Regulation Mechanisms from Whole Plant to Cell. Ann. Bot. 2009, 103, 551-560. [CrossRef]

55. Bairu, M.W.; Aremu, A.O.; Van Staden, J. Somaclonal Variation in Plants: Causes and Detection Methods. Plant Growth Regul. 2011, 63, 147-173. [CrossRef]

56. Ma, Y.; Dias, M.C.; Freitas, H. Drought and Salinity Stress Responses and Microbe-Induced Tolerance in Plants. Front. Plant. Sci. 2020, 11, 1750. [CrossRef] [PubMed]

57. Shah, H.; Houborg, R.; McCabe, M. Response of Chlorophyll, Carotenoid and SPAD-502 Measurement to Salinity and Nutrient Stress in Wheat (Triticum Aestivum L.). Agronomy 2017, 7, 61. [CrossRef]

58. Ashraf, M.; Harris, P.J.C. Photosynthesis under Stressful Environments: An Overview. Photosynthetica 2013, 51, 163-190. [CrossRef]

59. Ibrahim, M.H.; Jaafar, H.Z. Abscisic Acid Induced Changes in Production of Primary and Secondary Metabolites, Photosynthetic Capacity, Antioxidant Capability, Antioxidant Enzymes and Lipoxygenase Inhibitory Activity of Orthosiphon Stamineus Benth. Molecules 2013, 18, 7957-7976. [CrossRef] [PubMed]

60. Khalil, R.; Nagah, A.; Bassuony, F.; Haroun, S.A. Kinetin and/or Calcium Affect Growth of Phaseolus vulgaris L. Plant Grown under Heavy Metals Stress. J. Environ. Sci. 2017, 46, 103-120.

61. Falqueto, A.R.; Silva, F.S.; Cassol, D.; Magalhães, A.M., Jr.; Oliveira, A.C.; Bacarin, M.A. Chlorophyll Fluorescence in Rice: Probing of Senescence Driven Changes of PSII Activity on Rice Varieties Differing in Grain Yield Capacity. Braz. J. Plant. Physiol. 2010, 22, 35-41. [CrossRef]

62. Zivcak, M.; Brestic, M.; Olsovska, K.; Slamka, P. Performance Index as a Sensitive Indicator of Water Stress in Triticum aestivum L. Plant Soil Environ. 2008, 54, 133-139. [CrossRef]

63. Ceusters, N.; Valcke, R.; Frans, M.; Claes, J.E.; Van den Ende, W.; Ceusters, J. Performance Index and PSII Connectivity under Drought and Contrasting Light Regimes in the CAM Orchid Phalaenopsis. Front. Plant. Sci. 2019, 10. [CrossRef] [PubMed]

64. Strasser, R.; Tsimilli-Michael, M.; Srivastava, A. Analysis of the Chlorophyll a Fluorescence Transient. In Chlorophyll Fluorescence: A Signature of Photosynthesis, Advances in Photosynthesis and Respiration; Springer: Berlin/Heildelberg, Germany, $2004 ;$ pp. 321-362. [CrossRef]

65. Akhter, M.S.; Noreen, S.; Mahmood, S.; Athar, H.-U.; Ashraf, M.; Alsahli, A.A.; Ahmad, P. Influence of Salinity Stress on PSII in Barley (Hordeum vulgare L.) Genotypes, Probed by Chlorophyll-A Fluorescence. J. King Saud Univ.-Sci. 2020, 33, 101239. [CrossRef]

66. Demetriou, G.; Neonaki, C.; Navakoudis, E.; Kotzabasis, K. Salt Stress impact on the Molecular Structure and Function of the Photosynthetic Apparatus-The Protective Role of Polyamines. Biochim. Biophys. Acta 2007, 1767, 272-280. [CrossRef] [PubMed] 